\title{
A prediction model for vertical-to-horizontal spectral ratios of ground motions on the seafloor for moderate magnitude events for the Sagami Bay region in Japan
}

\author{
Jingyang Tan • Jinjun Hu $\mathbb{C}$
}

Received: 28 February 2020 / Accepted: 28 May 2020 /Published online: 24 June 2020

(C) The Author(s) 2020

\begin{abstract}
A prediction model for offshore vertical-tohorizontal $(V / H)$ spectral ratios of peak ground acceleration (PGA) and 5\%-damped elastic response spectra for periods ranging from 0.01 to $10 \mathrm{~s}$ for an offshore area off Sagami Bay was developed. To compare differences between offshore and onshore ground motions in the $\mathrm{V} /$ $H$ spectral ratios, an onshore $V / H$ prediction model was derived for onshore stations adjacent to the studied offshore sites. The offshore dataset includes 738 threecomponent records, and the onshore dataset includes 2219 records; both datasets are derived from the same set of 233 earthquakes selected for this study. The moment magnitude, hypocentral distance, focal depth, tectonic source type, and individual site correction term are used as independent variables in the $V / H$ models. A comparison drawn between the offshore and onshore models shows that the $V / H$ spectral ratios of offshore ground motions are obviously smaller than those of the onshore motions over short periods $(<1.0 \mathrm{~s})$ but are comparable for periods of longer than $1.0 \mathrm{~s}$. Water layer reduces vertical ground motions, especially over short periods, and as the periods increase, the effect of water layer decreases. The effect of the moment magnitude on offshore $\mathrm{V} / \mathrm{H}$ ratios is stronger than that of onshore ratios, especially for long periods; the effect of hypocentral distance and focal depth is considerable for long
\end{abstract}

J. Tan $\cdot$ J. Hu $(\bowtie)$

Key Laboratory of Earthquake Engineering and Engineering Vibration, Institute of Engineering Mechanics,, China Earthquake Administration, Harbin 150080, China

e-mail: hu-jinjun@163.com periods for offshore $V / H$ ratios, and the $V / H$ ratios between offshore sites are very different due to complex local site geologies beneath the offshore stations.

Keywords Offshore ground motion - Vertical-tohorizontal ratio model $\cdot V / H$ spectral ratio $\cdot \mathrm{PGA} \cdot$ Sagami Bay

\section{Introduction}

Earthquake ground motions on the seafloor differ from onshore ground motions in vertical components and vertical-to-horizontal $(V / H)$ response spectral ratios (Chen et al. 2015). The characteristics of offshore ground motion have been investigated by some investigators, and vertical offshore ground motion values have been found to be much lower than those of horizontal offshore ground motion (e.g., Boore and Smith 1999; Chen et al. 2017; Diao et al. 2014; Li et al. 2015); thus, the vertical-to-horizontal peak ground acceleration (PGA) and spectral ratios of offshore ground motions are considerably different from those of onshore ground motions.

Offshore stations are mainly located in the USA and Japan (e.g., the Earthquake and Tsunami Monitoring Cable (ETMC) of the K-NET in Sagami Bay (Eguchi et al. 1998), the Seafloor Earthquake Measuring System (SEMS) off the coast of southern California (Boore and Smith 1999), the Dense Ocean Network for Earthquake and Tsunamis (DONET) in the Nankai Trough in Japan (Kaneda et al. 2015), and the Seafloor Observation 
Network for Earthquakes and Tsunamis (S-net) along the Japan Trench (Kanazawa 2013)). Boore and Smith (1999) analyzed the $V / H$ spectral ratios of Fourier amplitude spectra and response spectra for the offshore ground motion obtained from SEMS instruments. The offshore ground motion reported in their study showed very low-amplitude vertical components compared to those of the onshore motion and particularly for short periods; however, due to a lack of onshore records for distances comparable to those taken from sources to the SEMS sites, they did not present a direct comparison of offshore and onshore records. Diao et al. (2014) studied the effect of water layer on the vertical components of offshore ground motions via a theoretical method using the same offshore records employed by Boore and Smith (1999). They concluded that water layer can reduce the vertical component amplitudes of offshore ground motions, consistent with Boore and Smith (1999). Li et al. (2015) proposed a method for modeling and simulating the offshore ground motion, and their results showed that the vertical ground motions on the seafloor are suppressed near the P-wave resonant frequencies. Chen et al. $(2015,2017)$ selected eight earthquakes recorded by the Kyoshin network (K-NET) to analyze horizontal normalized response spectra and $V / H$ response spectral ratios using 36 offshore records from six offshore stations throughout the Sagami Bay and 31 onshore records from eight onshore stations adjacent to those offshore stations. Their results revealed that the normalized response spectra and $V / H$ response spectral ratios of the offshore ground motions were different from those of the onshore motions. Moreover, $V / H$ ratios at short periods for the offshore ground motions were much lower than those for the onshore motions. Nevertheless, as they examined only a few earthquakes and 36 offshore records, they did not identify how explanatory variables, such as the magnitude and hypocentral distance, affect the $V / H$ spectral ratios. Dhakal et al. (2017) processed 315 earthquakes recorded at the same six K-NET offshore stations to compute the mean S-wave horizontal-to-vertical $(\mathrm{S}-H / V)$ spectral ratios of weak ground motions and compared these to the $\mathrm{S}-H / V$ spectral ratios of strong ground motions. Their results indicated that the six offshore stations exhibited nonlinear responses during strong earthquakes and that the PGA threshold causing a nonlinear site response differed from site to site, mainly because the underlying site geology is not uniform beneath the offshore sites. We know from their study that the differences in $V / H$ spectral ratios observed between the offshore stations are largely due to varying local site conditions. The ground motion prediction equation (GMPE) of offshore sites is different from that of onshore stations (Hu et al. 2020), and we have presented a direct comparison of $\mathrm{V} / \mathrm{H}$ spectral ratios of the offshore and onshore ground motion, from which we can understand how $V / H$ spectral ratios vary by period, moment magnitude, hypocentral distance, etc.

Prediction models for $V / H$ spectral ratios of different onshore areas have been proposed by several researchers (e.g., Bommer et al. 2011; Gülerce and Abrahamson, 2011; Bozorgnia and Campbell 2016; Soghrat and Ziyaeifar 2016; Zolfaghari and Darzi 2019a) who have examined the relationships between horizontal and vertical components of onshore ground motions and pointed out that a prediction equation for $V /$ $H$ ratios is needed in the probabilistic seismic hazard analysis (PSHA). The $V / H$ ratio can be estimated from independent GMPEs for vertical and horizontal components developed from the same dataset and functional forms (e.g., Boore et al. 2014; Stewart et al. 2016; Zolfaghari and Darzi 2019b). However, this approach cannot obtain the residuals and standard deviations of $V /$ $H$ ratios, and therefore, the direct estimation of $V / H$ ratios using regression analysis from a ground motion dataset has been proposed (e.g., Zolfaghari and Darzi 2019b). Furthermore, Akkar et al. (2014) pointed out that the direct estimation of $V / H$ ratios can preserve the better consistency between horizontal and vertical components than those obtained from independent horizontal and vertical GMPEs.

The American Petroleum Institute (API) showed that the seismic analysis of a fixed offshore platform should input a combination of vertical and horizontal ground motions and that a $V / H$ ratio of 0.5 is recommended (RP2A-WSD 2014). Simplified period-dependent models for $V / H$ or even a constant $V / H$ ratio is used in some codes to obtain a vertical response spectrum from corresponding horizontal spectrum (Zolfaghari and Darzi 2019b), and therefore, Chen et al. (2017) analyzed vertical-to-horizontal response spectral ratios for offshore ground motions by presenting the mean $V / H$ ratios of nine earthquakes and proposed a simplified design equation for the $V / H$ ratio of offshore ground motions, in which only the moment magnitude and the perioddependent variation are considered. However, the simplified equation proposed by Chen et al. (2017) does not consider the differences in $V / H$ ratios between offshore 
stations due to varying local site geologies of offshore stations (Dhakal et al. 2017). As we found that the suggested $V / H$ ratios by Chen et al. (2017) are lower for some offshore stations, we attempt to develop a more appropriate $\mathrm{V} / \mathrm{H}$ model for offshore ground motions for the Sagami offshore region, and the proposed offshore $\mathrm{V} / \mathrm{H}$ model is used to facilitate the assessment of response spectra of vertical components using $V / H$ ratios when the horizontal component of the response spectrum is known.

In this article, a prediction model for $V / H$ ratios for the offshore area off Sagami Bay in Japan is developed based on all available offshore records. We first analyze the correlation between offshore $V / H$ ratios with the moment magnitude, hypocentral distance, focal depth, and tectonic source type by dividing the offshore dataset into different groups based on previous research methods on the $V / H$ prediction model. To directly compare the differences in $V / H$ ratios of the offshore and onshore ground motions of this region, the onshore $\mathrm{V} / \mathrm{H}$ ratio prediction model is also proposed based on onshore records pertaining to the same set of earthquakes. To account for differences in local site conditions, individual site correction terms are used for the offshore sites in the offshore $V / H$ model due to unavailable site condition data while site class terms are used for the onshore sites in the onshore model. The $V / H$ ratios are defined as a function of the magnitude, hypocentral distance, focal depth, tectonic source type, and site conditions. The validity of the proposed models is examined by a detailed residual analysis, and the analysis shows that the offshore $V / H$ model is not biased with regard to the moment magnitude, hypocentral distance, or focal depth. The results of direct comparisons show that the $\mathrm{V} / \mathrm{H}$ ratios of offshore motions are significantly smaller than those of onshore motions for short moderate spectral periods $(T<1.0 \mathrm{~s})$ and are comparable for periods longer than $1.0 \mathrm{~s}$.

\section{Strong ground motion database}

There are six offshore sites, namely KNG201, KNG202, KNG203, KNG204, KNG205, and KNG206, deployed below the seafloor off Sagami Bay. We examined these 6 offshore sites of the K-NET ETMC network in addition to 23 onshore stations from K-NET adjacent to the offshore area. Figure 1 shows the distributions of the offshore sites, onshore sites, and earthquakes used in this study. Filled circles indicate earthquake epicenters, the colors of the circles denote the focal depths of the earthquakes, red squares denote the 6 offshore sites, and black triangles denote the 23 onshore stations. The background color denotes the elevation of the land and seafloor with the deepest elevation denoted by the darkest color. The distances between two adjacent offshore sites range from 10 to $20 \mathrm{~km}$, and the water depths of these offshore sites range from approximately 900 to $2300 \mathrm{~m}$. Detailed information about the deployment of the offshore sites used in this study can be found in Eguchi et al. (1998). Table 1 presents detailed information corresponding to the offshore and onshore sites used in this study. All strong motion records from the offshore and onshore sites and corresponding soil condition data, including P-wave and S-wave logs and standard penetration test values, are available on the K-NET website (http://www.kyoshin.bosai.go.jp/, last accessed June 2019) (Aoi et al. 2004).

All available events recorded by the six offshore stations from earthquakes occurring between 2000 and 2018 were examined in this study. We excluded some offshore records using the following criteria: records must include both $\mathrm{P}$-wave and $\mathrm{S}$-wave onsets, the signal-to-noise ratio (SNR) of the three components of the records should be greater than 3 for each component, the source-to-site distance (epicentral distance) must be less than $300 \mathrm{~km}$, the focal depth must be shallower than $180 \mathrm{~km}$, and the moment magnitude must not be smaller than 4.0. The dataset of offshore strong ground motions includes 738 three-component records from 233 events. In order to directly compare the differences of the $V / H$ ratios between the offshore and onshore ground motions, onshore strong ground motions are also selected from the same set of earthquakes employed for the offshore dataset. Therefore, the dataset of onshore strong motions includes 2219 three-component onshore records from the same 233 events. Detailed information regarding the earthquake events used in this study can be found in $\mathrm{Hu}$ et al. (2020).

For the onshore stations studied here, we only have soil condition data for a depth range of 10-20 m, so the travel-time averaged shear-wave velocity to $30 \mathrm{~m}$ (VS30) is estimated using the extrapolation relations proposed by Boore et al. (2011). The estimated VS30 values for the onshore sites are listed in Table 1 . Then, according to the estimated VS30 values, the onshore sites are categorized into four site classes, SC I, SC II, SC III, and SC IV, approximately corresponding to four 
Fig. 1 Geographic distribution map of earthquakes and strong ground motion recording stations around Sagami Bay in Japan.

Triangles and squares denote the offshore and onshore stations in the Sagami Bay area,

respectively, and circles, scaled by moment magnitude, denote the earthquake epicenters used in this study. The colors of the circles denote the focal depths of the earthquakes. Background colors denote elevations of the land and seafloor with the deepest elevation denoted by the darkest color

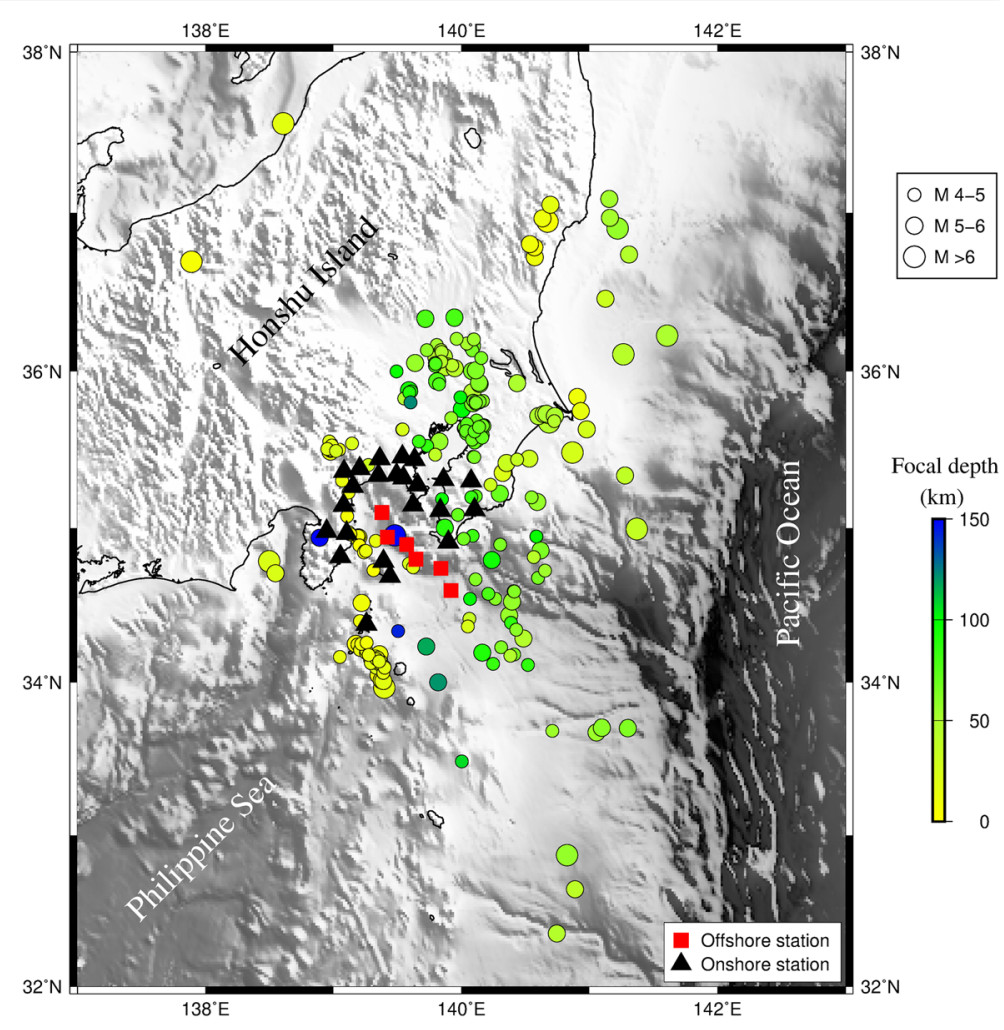

classes of rock, hard soil, medium soil, and soft soil, respectively, as defined by Molas and Yamazaki (1995). Table 2 shows the site class definitions, and Table 1 shows the site codes of the onshore stations relating to the corresponding site classes.

Japan is located above an active subduction zone, and many earthquakes occurring therein are associated with activity within and between the upper and lower tectonic plates. As the attenuation characteristics of different subduction-type earthquakes have been recognized (e.g., Youngs et al. 1997; Morikawa and Sasatani, 2004; Abrahamson et al. 2016), subduction earthquakes are typically classified as either subduction interface earthquakes or subduction slab earthquakes with respect to the tectonic source type. Therefore, the earthquake events used in this study are classified as crustal, interface, and slab events according to their locations (i.e., their epicentral locations and focal depths) with respect to the trench axis and their focal mechanisms. The results of the classification show that, in general, slab events are associated with normal-faulting events at focal depths of deeper than $50 \mathrm{~km}$ whereas interface events are associated with reverse-faulting events and are located between the coast and the trench axis at focal depths shallower than $50 \mathrm{~km}$ (Zhao et al. 2006; Montalva et al. 2017). In contrast, crustal events are characterized by either normal or strike-slip faulting mechanisms and focal depths shallower than $50 \mathrm{~km}$. The focal mechanisms are differentiated based on a rake angle criterion (Boore et al. 1997). Rake angles within $30^{\circ}$ of the horizontal are classified as strike-slip events while angles of 30 to $150^{\circ}$ are regarded as reversefaulting events, and angles of -30 to -150 are categorized as normal-faulting events. For a few events, the boundary values are adjusted based on the overall mechanism and tectonic environment involved. The epicentral coordinates and focal depths of the events are obtained from the Japan Meteorological Agency (JMA) while their moment magnitudes and focal mechanism solutions are obtained from the Full Range Seismograph Network of Japan (F-net) operated by the National Research Institute for Earth Science and Disaster Prevention (NIED). The source categories of the events can also be found in $\mathrm{Hu}$ et al. (2020).

Figure $2 \mathrm{a}$ and $\mathrm{b}$ show the distributions of the event magnitude and hypocentral distance for the earthquakes with focal depths reaching $180 \mathrm{~km}$ for the offshore and onshore strong motion datasets, respectively. The 
Table 1 Information on the offshore sites and onshore stations used in this study

\begin{tabular}{|c|c|c|c|c|c|c|}
\hline Network & Site code & Latitude & Longitude & Water depth (m) & VS30 (m/s) & Site class \\
\hline K-NET & KNG201 & $34.5956 \mathrm{~N}$ & $139.9183 \mathrm{E}$ & 2197 & No data & - \\
\hline K-NET & KNG202 & $34.7396 \mathrm{~N}$ & $139.8393 \mathrm{E}$ & 2339 & No data & - \\
\hline K-NET & KNG203 & $34.7983 \mathrm{~N}$ & $139.6435 \mathrm{E}$ & 902 & No data & - \\
\hline K-NET & KNG204 & $34.8931 \mathrm{~N}$ & $139.5711 \mathrm{E}$ & 933 & No data & - \\
\hline K-NET & KNG205 & $34.9413 \mathrm{~N}$ & $139.4213 \mathrm{E}$ & 1486 & No data & - \\
\hline K-NET & KNG206 & $35.0966 \mathrm{~N}$ & $139.3778 \mathrm{E}$ & 1130 & No data & - \\
\hline K-NET & CHB021 & 34.9083 & 139.8979 & Onshore & 685.5135 & I \\
\hline K-NET & CHB022 & 35.3083 & 139.8598 & Onshore & 312.1377 & II \\
\hline K-NET & KNG003 & 35.2727 & 139.6579 & Onshore & 460.9594 & II \\
\hline K-NET & KNG005 & 35.3192 & 139.5462 & Onshore & 446.8882 & II \\
\hline K-NET & KNG006 & 35.4544 & 139.5387 & Onshore & 353.6757 & II \\
\hline K-NET & KNG007 & 35.3382 & 139.4926 & Onshore & 433.6031 & II \\
\hline K-NET & KNG010 & 35.3355 & 139.3504 & Onshore & 437.2491 & II \\
\hline K-NET & KNG012 & 35.3794 & 139.2048 & Onshore & 483.6154 & II \\
\hline K-NET & KNG014 & 35.3608 & 139.0826 & Onshore & 438.2018 & II \\
\hline K-NET & SZO001 & 35.1424 & 139.0795 & Onshore & 469.5589 & II \\
\hline K-NET & SZO002 & 34.9652 & 139.1031 & Onshore & 368.4688 & II \\
\hline K-NET & SZO007 & 34.9771 & 138.9466 & Onshore & 540.7971 & II \\
\hline K-NET & TKY008 & 34.7852 & 139.3909 & Onshore & 452.7404 & II \\
\hline K-NET & TKY009 & 34.6874 & 139.4412 & Onshore & 339.9597 & II \\
\hline K-NET & TKY010 & 34.3779 & 139.2573 & Onshore & 310.6555 & II \\
\hline K-NET & СHB017 & 35.2988 & 140.0755 & Onshore & 261.9185 & III \\
\hline K-NET & KNG004 & 35.1441 & 139.6218 & Onshore & 254.8754 & III \\
\hline K-NET & SZO003 & 34.8158 & 139.0546 & Onshore & 256.0615 & III \\
\hline K-NET & СHB019 & 35.1105 & 139.8351 & Onshore & 153.2703 & IV \\
\hline K-NET & CHB020 & 35.1155 & 140.1022 & Onshore & 187.6301 & IV \\
\hline K-NET & KNG002 & 35.4371 & 139.634 & Onshore & 116.615 & IV \\
\hline K-NET & KNG009 & 35.4424 & 139.3618 & Onshore & 146.2693 & IV \\
\hline K-NET & KNG013 & 35.2641 & 139.152 & Onshore & 91.04945 & IV \\
\hline
\end{tabular}

moment magnitudes of the events range from 4.0 to 6.8 , and the hypocentral distances are less than $300 \mathrm{~km}$. Within the offshore dataset, only a few records pertain to events occurring within a $30-\mathrm{km}$ hypocentral distance, and no events were recorded within a $15-\mathrm{km}$ hypocentral distance. Therefore, our offshore $V / H$ model may not be appropriate for near-source earthquake prediction. Figure $2 \mathrm{c}$ and $\mathrm{d}$ show the distributions of the event magnitude and focal depth for the offshore and onshore datasets, respectively. The distributions of the

Table 2 Site classification method used in the present study for onshore stations

\begin{tabular}{lll}
\hline Site classes & Average shear wave velocity & NEHPR class \\
\hline SC I:(rock/stiff soil) & VS $30>600 \mathrm{~m} / \mathrm{s}$ & A + B \\
SC II: (hard soil) & $300 \mathrm{~m} / \mathrm{s}<\mathrm{VS} 30 \leq 600 \mathrm{~m} / \mathrm{s}$ & $\mathrm{C}$ \\
SC III: (medium soil) & $200 \mathrm{~m} / \mathrm{s}<\mathrm{VS} 30 \leq 300 \mathrm{~m} / \mathrm{s}$ & $\mathrm{D}$ \\
SC IV: (soft soil) & VS $30 \leq 200 \mathrm{~m} / \mathrm{s}$ & E \\
\hline
\end{tabular}


offshore and onshore magnitudes and focal depths show reasonable levels of agreement. The offshore dataset includes 233 events, and the onshore dataset includes 223 events. Ten events are excluded from the onshore dataset because either the hypocentral distance exceeds $300 \mathrm{~km}$ or the SNRs of the records are smaller than 3.

Nearly all records obtained from the K-NET have baseline offsets and are contaminated with noise. Therefore, applying the processing method developed by Boore et al. (2002) and Boore and Bommer 2005, we use a simple scheme to process the records for each component as clearly stated in $\mathrm{Hu}$ et al. (2020). Numerical experiments show that the acceleration response spectra calculated from the accelerograms are not sensitive to the choice of the low-cut frequencies for oscillator periods of less than $0.5 / \mathrm{fc}$, where $\mathrm{fc}=0.05 \mathrm{~Hz}$ is suitable for computed spectral accelerations for periods of less than or equal to $10 \mathrm{~s}$. The sampling rate of these records is either $50 \mathrm{~Hz}$ or $100 \mathrm{~Hz}$, and thus, a high-cut frequency of $25 \mathrm{~Hz}$ is used to eliminate ground motions over $25 \mathrm{~Hz}$. This high-cut frequency is determined by examining the Fourier spectra of all available records, thereby demonstrating that the main part of each record is retained in the selected frequency band.

\section{Exploration of functional form}

To understand the effect of these explanatory variables, i.e., the moment magnitude, hypocentral distance, focal depth, and tectonic source type, on the offshore $V / H$ ratios, a preliminary analysis of these $V / H$ ratios with respect to different magnitude, distance, depth, and source type groups are compared over varying periods. Figure 3 shows the observed trends in the offshore $V / H$ ratios with respect to different groups. As shown in Fig. 3a, the offshore $V / H$ ratios are divided into three groups by three magnitudes, i.e., magnitudes of less than 5.0, between 5.0 and 6.0, and larger than 6.0, and the mean offshore $V / H$ ratios of each group are plotted as varying with periods with different line styles. Figure $3 b-d$ show the varying trends of the offshore $\mathrm{V} / \mathrm{H}$ ratios with periods for different hypocentral distance, focal depth, and tectonic source type groups, respectively. The mean offshore $V / H$ ratio ordinates are comparable for periods of shorter than $1.0 \mathrm{~s}$ for different magnitude, distance, depth, and source type groups, but as the period increases, the mean offshore $V /$ $H$ ratio changes for all groups. The mean offshore $V / H$ ratio changes with the moment magnitude in periods lasting longer than $1.0 \mathrm{~s}$. The larger the moment magnitude, the larger the offshore $V / H$ ratios. Differences are also found between the mean offshore $V / H$ ratio for PGA and spectral periods of less than $0.05 \mathrm{~s}$. The varying trends for different hypocentral distance groups are not obvious for periods longer than $2.0 \mathrm{~s}$ with the main difference being that the mean $\mathrm{V} / \mathrm{H}$ ratio of the group for distances longer than $160 \mathrm{~km}$ is significantly larger than those of the other two groups with short moderate hypocentral distances for periods lasting longer than $2.0 \mathrm{~s}$. For the effect of focal depth, the mean $\mathrm{V} / \mathrm{H}$ ratio of depths of deeper than $60 \mathrm{~km}$ is smaller for the other two groups for periods longer than $1.0 \mathrm{~s}$ and is similar to those for periods of less than $1.0 \mathrm{~s}$. We can confirm that the deeper the focal depth, the smaller the offshore $V / H$ ratio, mainly for long periods (>1.0 s). The tectonic source type also affects the offshore $V / H$ ratio mainly for long periods. Therefore, the moment magnitude, hypocentral distance, focal depth, and earthquake type have little effect on the offshore $V / H$ ratio for periods ranging from 0.05 to $1.0 \mathrm{~s}$; however, these explanatory variables apparently have an effect for periods of longer than $1.0 \mathrm{~s}$ and have moderate effects on offshore $V / H$ ratios for periods of less than $0.05 \mathrm{~s}$.

To compare differences in the effects of these variables on $\mathrm{V} / \mathrm{H}$ ratios of the offshore and onshore ground motions, the varying trends of the mean onshore $\mathrm{V} / \mathrm{H}$ ratios for different groups are presented in Fig. 4. The differences in onshore $\mathrm{V} / \mathrm{H}$ ratio across these groups are not large for the entire period band, and the overall effects of these explanatory variables on the mean onshore $\mathrm{V} / \mathrm{H}$ ratios are not as clear as those shown in Fig. 3. The effect level of these variables on the onshore $V / H$ ratio is similar to those presented for other onshore regions (Bommer et al. 2011; Zolfaghari and Darzi 2019a). The spectral shapes of the offshore and onshore $\mathrm{V} / \mathrm{H}$ ratios are significantly different, and the effects of variables on the $V / H$ ratios are also not consistent. To find the best functional form and to avoid overcomplicating the form of the offshore $V / H$ model, varying trends of the offshore $V / H$ ratio with magnitude, distance, depth, and source type are investigated in Fig. 3 and compared to the onshore $V / H$ ratios given in Fig. 4. Therefore, these variables are considered in the $\mathrm{V} / \mathrm{H}$ prediction model by using a simple functional form.

The characteristics of the observed offshore ground motion are considerably different from those of the onshore motions, but as soil condition data for the offshore sites are unavailable, an analysis of the site effect by the VS30 cannot be applied to the offshore sites. Therefore, 

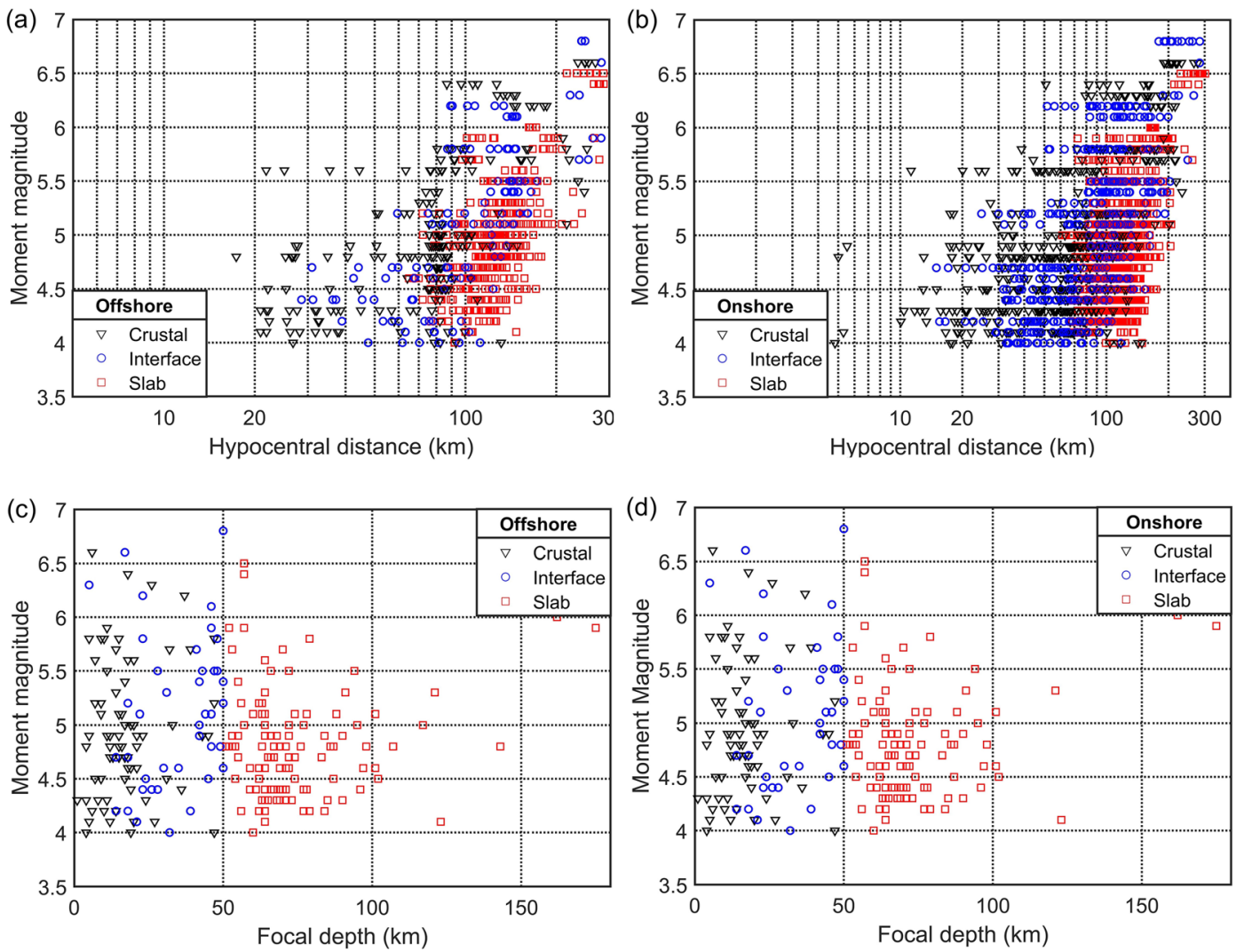

Fig. 2 Magnitude and distance or depth distributions of the offshore and onshore ground motions used in the present study

we refer to the individual site term method of Takahashi et al. (2004) for the six offshore sites. Although the processing method of individual site terms is not the best for analyzing the offshore $\mathrm{V} / \mathrm{H}$ ratio in considering the site effect, the individual site terms here could not only reduce the total sigma of the model by our preliminary analysis but also show differences between the offshore sites due to the different local site geologies present (Dhakal et al. 2017). As for the onshore stations, they are classified into four classes according to the obtained VS30 of these onshore stations as shown in Table 1.

Chen et al. (2017) presented a simplified design equation of offshore ground motion using only 54 offshore recordings. In their analysis, the mean $\mathrm{V} / \mathrm{H}$ ratio of the six offshore sites is used, but according to Dhakal et al. (2017), the site geologies of offshore sites are not uniform, and therefore, the mean $V / H$ ratio of offshore sites introduces uncertainty for predicting the offshore $\mathrm{V} / \mathrm{H}$ ratio, and the prediction equation should be derived from more than 54 recordings. Although all available offshore ground motion records are used to develop the offshore $V / H$ model in this study, the offshore dataset cannot provide robust constraint due to limited offshore records as shown in Fig. 2a. Therefore, we collected all available offshore recordings for the offshore area off Sagami Bay and fully considered the effects of the explanatory variables on the offshore $V / H$ ratio.

The response spectra of the vertical offshore motion are much lower than those of the horizontal offshore motion mainly due to the effect of water layer (Boore and Smith 1999; Chen et al. 2015, 2017; Diao et al. 2014). The behaviors of median $V /$ $H$ ratios as functions of independent variables are investigated in Fig. 3. While referring to the prediction $V / H$ ratio model developed by Gülerce and Abrahamson (2011) based on the Pacific Earthquake Engineering Research-Next Generation Attenuation of Ground Motions (PEER NGA) dataset and the prediction model for $V / H$ ratios for Europe and the Middle East developed by Bommer et al. (2011), we considered the effect of the moment magnitude, hypocentral distance, focal depth, and tectonic source type on the offshore $\mathrm{V} / \mathrm{H}$ ratio in the base functional form presented in Eq. (1): 
(a)

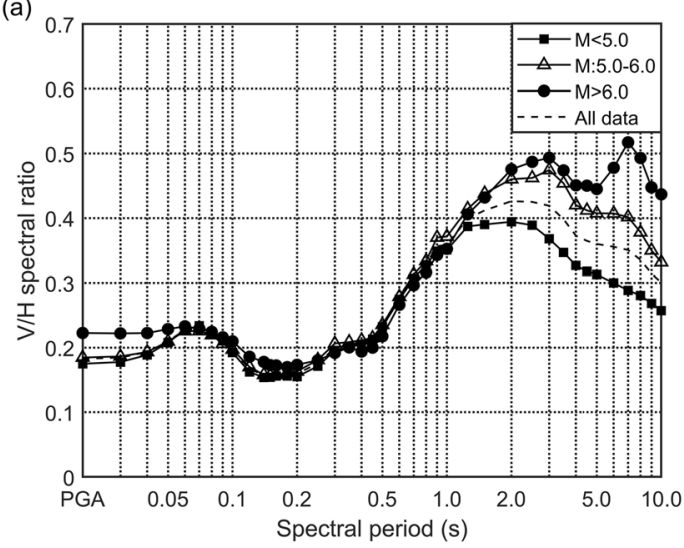

(c)

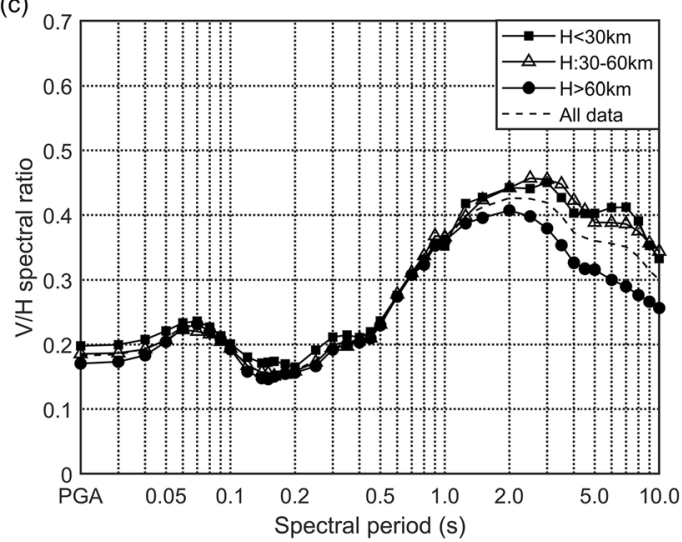

(b)

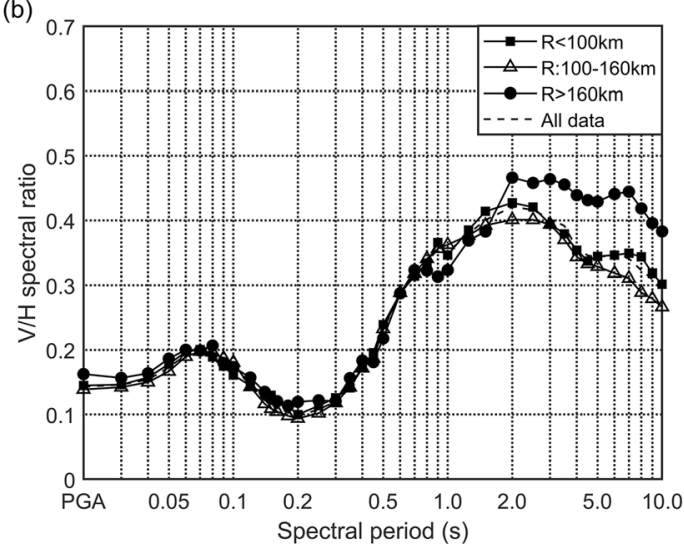

(d)

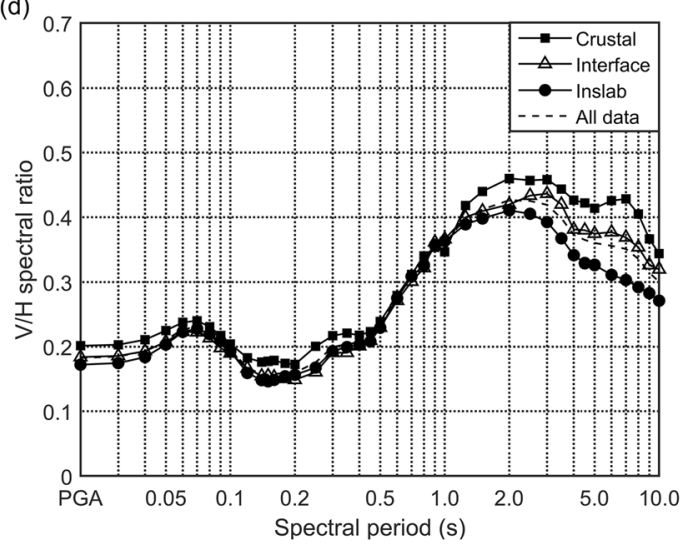

Fig. 3 Preliminary analysis of offshore ground motion $V / H$ ratios for different magnitude groups (a), hypocentral distance groups (b), focal depth groups (c), and earthquake type groups (d)

$$
\begin{aligned}
\ln (V / H)= & b_{1} M_{w}+b_{2} M_{w}^{2} \\
& +\left(b_{3}+b_{4} M_{w}\right) \ln \left(\sqrt{R^{2}}+b_{5}^{2}\right)+b_{6^{h}} \\
& +b_{7} F_{\mathrm{I}}+b_{8} F_{\mathrm{S}}+S_{k}+\mathrm{SC}_{p}
\end{aligned}
$$

in which $V / H$ is either $V / H$ PGA or the $5 \%$-damped $V / H$ spectral acceleration ratio at spectral period $T, M_{w}$ is the moment magnitude, $R$ is the hypocentral distance in kilometers, and $h$ is the focal depth in kilometers. $F_{\mathrm{I}}$ and $F_{\mathrm{S}}$ are the dummy variables for the tectonic source type. $F_{\mathrm{I}}=1.0$ for the interface events, and $F_{\mathrm{I}}=0$ for all other types of events; $F_{\mathrm{S}}$ is 1 for subduction slab events and is 0 for all other events. $S_{\mathrm{k}}$ is the individual site term for a given station applying to offshore stations only, and $S_{1}-S_{6}$ represent the individual site term corresponding to offshore sites KNG201-KNG206, respectively; $\mathrm{SC}_{p}$ is the site class term for a given site class applying to onshore stations only, and $\mathrm{SC}_{1}-\mathrm{SC}_{4}$ represent $\mathrm{SC}$ I$\mathrm{SC}$ IV site classes for the onshore sites, respectively. In many previous studies (Gülerce and Abrahamson 2011; Bommer et al. 2011; Soghrat and Ziyaeifar 2016; Zolfaghari and Darzi 2019a, 2019b), coefficient b5 is kept as $5 \mathrm{~km}$. Although the model is not well constrained over a short distance, the associated variability in our models is found to be at least as low as that obtained in other studies. When $h$ is deeper than $130 \mathrm{~km}$, $\mathrm{h}$ is set as $130 \mathrm{~km}$ so that a constant factor is used for deeper events. The horizontal PGA and horizontal spectral acceleration are both defined as the geometric mean of the two horizontal components.

The coefficients $b_{1}-b_{6}$, individual site term $S_{k}$, and site class term $\mathrm{SC}_{p}$ were determined by regression analysis for each period, and the regression results of the base model shown in Eq. (1) are analyzed, echoing overfitting results shown in Bommer et al. (2011) and Zolfaghari and Darzi (2019a). Therefore, coefficients $b_{2}$ and $b_{4}$ are set as 0 to obtain a more reasonable functional form. The preliminary analysis of the base model shows that the base model without $b_{2}$ and $b_{4}\left(b_{2}=b_{4}=0\right)$ can fit the offshore $V / H$ 
(a)

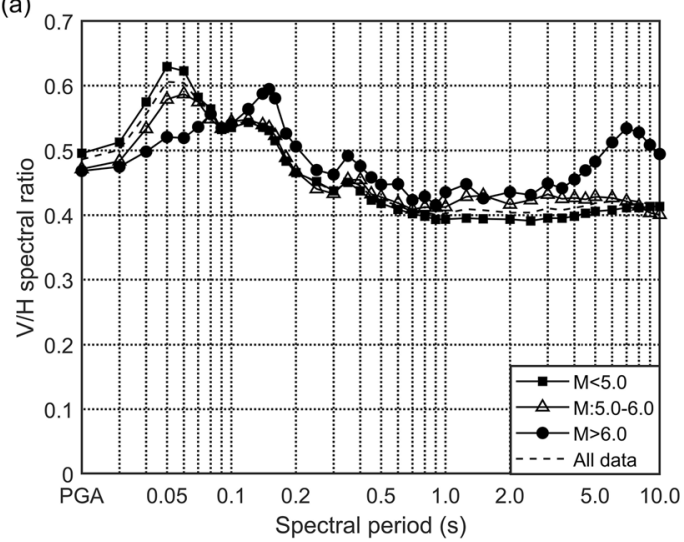

(c)

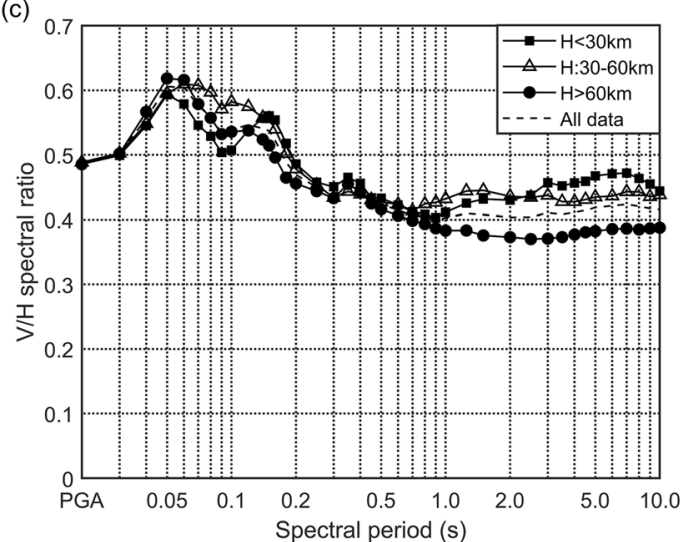

(b)

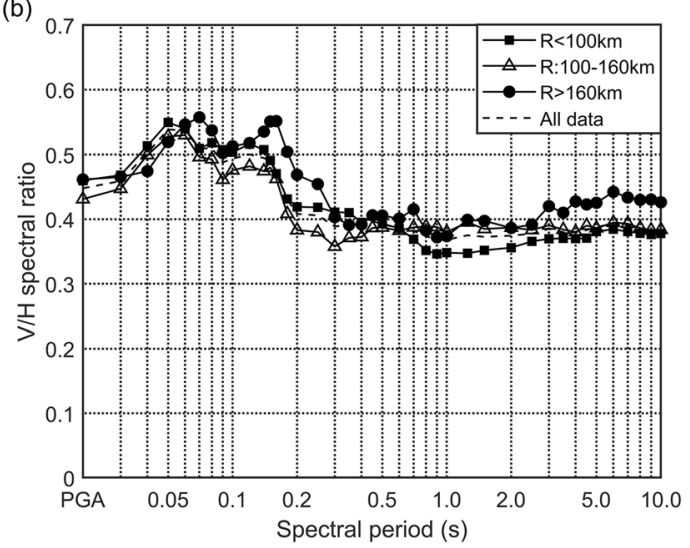

(d)

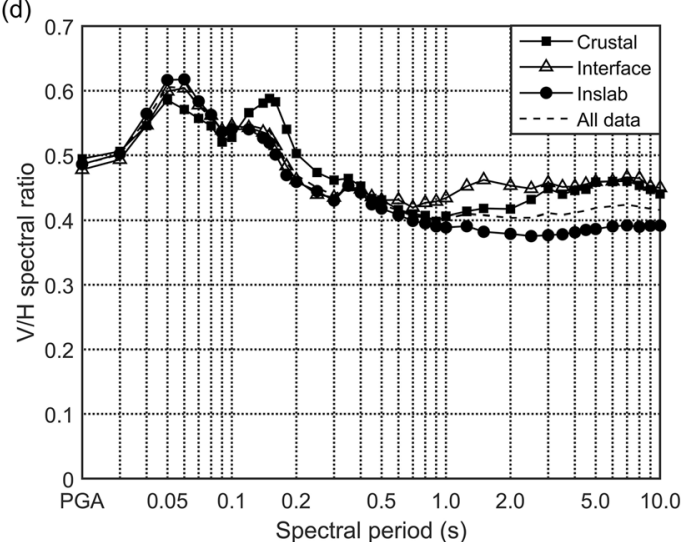

Fig. 4 Varying trends of onshore $V / H$ ratios for different magnitude (a), hypocentral distance (b), focal depth (c), and earthquake source type groups (d)

ratio model better than the base model with $b_{2}$ or $b_{4}$, mainly because the number of offshore recordings is so limited that the magnitude square term and magnitude related attenuation term were not well constrained.

\section{Regression analysis}

Regression analyses to estimate the offshore $V / H$ ratios for PGA and 5\%-damped spectral accelerations of up to $10.0 \mathrm{~s}$ are conducted for the base model without $b_{2}$ and $b_{4}$; in turn, the final prediction model for the offshore and onshore $V / H$ ratios is presented in Eq. (2):

$$
\begin{aligned}
\ln (V / H)= & b_{1} M_{w}+b_{3} \ln \left(\sqrt{R^{2}+b_{5}^{2}}\right) \\
& +b_{6}\left(h-h_{c}\right) \delta_{h}+b_{7} F_{\mathrm{I}}+b_{8} F_{\mathrm{s}}+S_{k} \\
& +\mathrm{SC}_{p}
\end{aligned}
$$

The random effect model proposed by Abrahamson and Youngs (1992) was used in the $V / H$ model of offshore and onshore ground motions, respectively. The total variability of the models can be expressed as the between-event (representing the event-to-event component of the total variability) and within-event (representing the site-to-site component of variability, path effects, and all other sources of variability not explicitly modeled) variability, and in this study, the between-event and within-event errors are assumed to be period dependent but independent of magnitude. Therefore, the model's total standard deviation can be calculated as

$\sigma_{T}+\sqrt{\sigma^{2}+\tau^{2}}$

in which $\sigma$ and $\tau$ are the within-event and between-event standard deviations, respectively.

The regression results of Eq. (2) on the offshore and onshore $V / H$ spectral ratio are presented in Tables 3 and 4 , respectively. The last three columns of Tables 3 and 4 list 
the within-event, between-event, and total standard deviations of the offshore and onshore $V / H$ model, respectively. Figure 5 shows the variations in the between-event, within-event, and total standard deviations for the offshore and onshore $V / H$ models with respect to the spectral periods. The largest total standard deviations for the offshore and onshore $\mathrm{V} / \mathrm{H}$ models are approximately 0.45 at $7.0 \mathrm{~s}$ and 0.48 at $0.25 \mathrm{~s}$, respectively. The between-event variability is a minor contributor to the total variability, as is generally found in empirical GMPEs (Strasser et al. 2009), and the between-event variability between the onshore and offshore models is similar. We can conclude from Fig. 5 that the level of total sigma found in this study is similar to those presented in the proposed $\mathrm{V} / \mathrm{H}$ models (Gülerce and Abrahamson 2011; Bommer et al. 2011; Zolfaghari and Darzi 2019a).

The validity of the offshore and onshore $V / H$ spectral ratio models was investigated by conventional residual analysis. Figures 6 and 7 show the between-event residuals against moment magnitude $M_{w}$ and focal depth, respectively, for PGA and spectral periods of $T=0.05$, $0.2,0.5,1.0$, and $3.0 \mathrm{~s}$. The red error bars shown in Figs. 6 and 7 indicate average residuals within predetermined magnitude bins and depth bins and their corresponding $\pm \sigma$ bounds. The distributions of between-event residuals are unbiased with respect to magnitude and focal depth, and only a slight bias is found for long periods and large magnitudes most likely due to the poor distribution of the data. Figure 8 shows the distribution of within-event residuals in terms of hypocentral distance for PGA and periods of $T=0.05,0.2,0.5,1.0$, and $3.0 \mathrm{~s}$. The distribution of the within-event residuals is unbiased within a hypocentral distance range of $15-300 \mathrm{~km}$. A residual analysis of the onshore $\mathrm{V} / \mathrm{H}$ model was also conducted and shows that the overall performance of the onshore model was well constrained. Therefore, the results of our analysis suggest that the offshore $V / H$ prediction model given in Eq. (2) can be used to predict offshore $V / H$ spectral ratios that are reasonably unbiased within a magnitude range of 4.0-7.8, a hypocentral distance of 15-300 km, and focal depths of 0-180 km.

\section{Predicted $\mathrm{V} / \mathrm{H}$ spectral ratios and comparison with the onshore $V / H$ model}

In this section, we first show how the magnitude, hypocentral distance, focal depth, and tectonic source type influence the offshore $V / H$ spectral ratio according to the regression results. To investigate the differences between the offshore and onshore $V / H$ ratios, the attenuation characteristics of the two models are compared with varying hypocentral distances and different moment magnitudes. Figure 9 shows the varying trends of the offshore and onshore $\mathrm{V} / \mathrm{H}$ ratios of given periods (PGA and $T=0.05,0.2,0.5,1.0$, and $3.0 \mathrm{~s}$ ) with the hypocentral distance by setting magnitudes of 4,5 , and 6 , respectively, focal depth of $20 \mathrm{~km}$, the tectonic source type of the crustal earthquake, an $S_{4}$ individual site term for offshore sites, and an $\mathrm{SC}_{2}$ site class term for onshore sites. The offshore $V / H$ ratios are denoted by black lines, and the onshore $V / H$ ratios are denoted by red lines in Fig. 9. Although the effect of the hypocentral distance is observed and this effect is different in different periods, the influence of hypocentral distance is not obvious. Moment magnitude effects for the offshore $V / H$ ratios are also observed for PGA, $T=0.05$, and $T=3.0 \mathrm{~s}$, which is consistent with trends observed in Fig. 3. The moment magnitude mainly affects the shortest periods $(T<0.05 \mathrm{~s})$ and longer periods $(T>1.0 \mathrm{~s})$, and the effect of the hypocentral distance is almost absent for short periods $(T<0.5 \mathrm{~s})$, and for long periods $(T>0.5 \mathrm{~s})$, a longer distance will always correspond with larger offshore $V / H$ ratios. The direct comparison of offshore and onshore $V / H$ ratios given in Fig. 9 shows that offshore $V /$ $H$ ratios are much lower than onshore $V / H$ ratios for periods of less than $0.5 \mathrm{~s}$, and for longer periods, obvious differences between them are not observed, which is mainly attributable to the water layer (Chen et al. 2015; Diao et al. 2014). As the number of offshore records is limited for constraining the offshore $\mathrm{V} / \mathrm{H}$ model, the physical explanation of the effects of these explanatory variables need further investigation after accounting for the effects of the water depth and the sediment thickness in the future with more offshore records.

Figure 10 shows the effects of the tectonic source type and focal depth on the $\mathrm{V} / \mathrm{H}$ ratios predicted from the offshore model. The basic model given in Eq. (2), i.e., where the source type and depth terms are both zero, is intended for crustal events with a focal depth of $15 \mathrm{~km}$ or less. Figure 10a shows that for periods of less than $0.1 \mathrm{~s}$, the offshore $V / H$ ratios show almost no differences with considering tectonic source types, i.e., crustal, interface, and slab earthquake events; beyond $0.1 \mathrm{~s}$, offshore $V / H$ ratios with interface events are smaller than those of the basic model with crustal events and represent approximately $80 \%$ of the offshore $V / H$ ratios drawn from the basic model for periods of longer than 


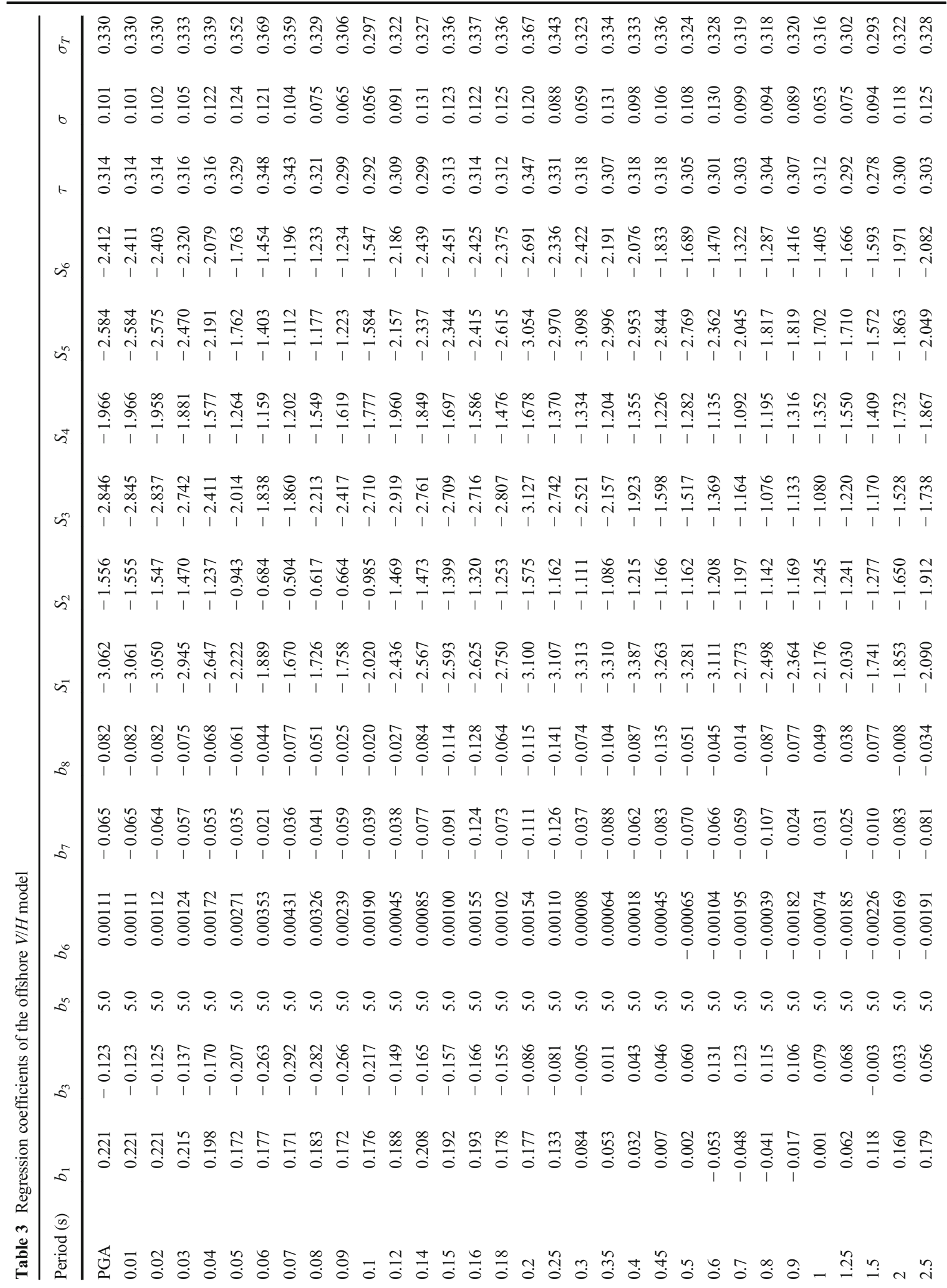




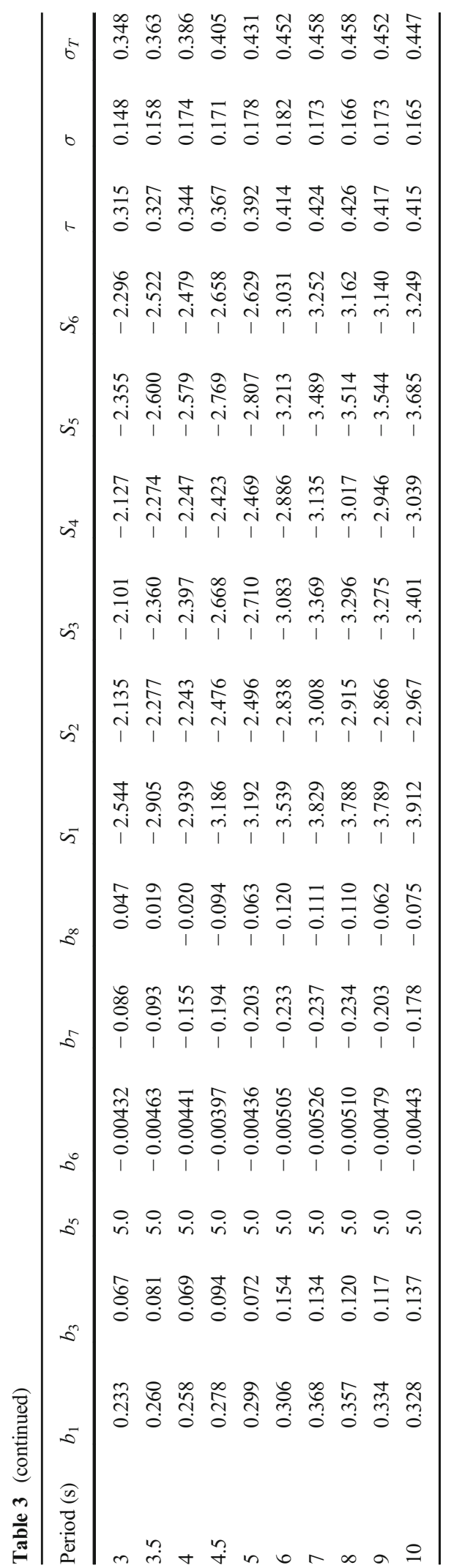

$3.0 \mathrm{~s}$. For slab events, the largest difference found between the basic model and the model with slab events is valued at roughly $10 \%$; therefore, the slab events do not seem to have a strong influence on the offshore $V / H$ ratios. Figure $10 \mathrm{~b}$ shows the effects of the focal depth on the proposed offshore $V / H$ model. The offshore $V / H$ ratio for the deeper depth is larger than that for the shallower depth for spectral periods of shorter than $0.5 \mathrm{~s}$ and is smaller than that of the shallower depth for periods of longer than $0.5 \mathrm{~s}$. Therefore, the effect of the focal depth is significant for the offshore $V / H$ model, but the effect of the tectonic source type seems to be insignificant for periods of less than $5.0 \mathrm{~s}$.

Figure 11 shows the variations in the predicted median $\mathrm{V} / \mathrm{H}$ response spectral ratios of the offshore and onshore ground motions for specific magnitude and distance combinations for a crustal event with a focal depth of $20 \mathrm{~km}$, using the $S_{1}$ individual site term for offshore sites and the $\mathrm{SC}_{2}$ site class term for onshore sites. The hypocentral distance seems to have little effect on the offshore and onshore $V / H$ ratios, but the magnitude significantly affects the offshore $V / H$ ratio for periods shorter than $0.05 \mathrm{~s}$ and longer than $1.0 \mathrm{~s}$. Most of the offshore $V / H$ ratios are smaller than the onshore $V / H$ ratios for spectral periods of less than $1.0 \mathrm{~s}$; then, the offshore $V / H$ ratios increase gradually to be comparable or even larger than the onshore $\mathrm{V} / \mathrm{H}$ ratio for periods of 1.0 to $3.0 \mathrm{~s}$, and for periods longer than $3.0 \mathrm{~s}$, the offshore $\mathrm{V} / \mathrm{H}$ ratios are slightly smaller than the onshore $\mathrm{V} / \mathrm{H}$ ratio, which is consistent with the preliminary analysis given in Figs. 3 and 4. The overall reduction found for short moderate periods $(T<1.0 \mathrm{~s})$ is mainly attributable to water layer and the deep deposition layer covering on the seafloor (Otsuka 1985; Chen et al. 2015; Hu et al. 2020). As Hu et al. (2020) stated in their study, both horizontal and vertical offshore response spectra are significantly larger than onshore response spectra, except that vertical response spectra for short moderate periods $(T<1.0 \mathrm{~s})$ are slightly smaller than those of onshore motions. The observed amplification in offshore ground motions and the large variability in offshore site responses show site-specific studies are needed for offshore structures (Hu et al. 2020). Hence, the offshore $V / H$ model can facilitate the construction of the vertical response spectrum in PSHA and can be used in seismic analysis for the combined input of vertical and horizontal ground motions. 
Table 4 Regression coefficients of the onshore $V / H$ model for comparison

\begin{tabular}{|c|c|c|c|c|c|c|c|c|c|c|c|c|c|}
\hline $\begin{array}{l}\text { Period } \\
\text { (s) }\end{array}$ & $b_{1}$ & $b_{3}$ & $b_{5}$ & $b_{6}$ & $b_{7}$ & $b_{8}$ & $S_{1}$ & $S_{2}$ & $S_{3}$ & $S_{4}$ & $\tau$ & $\sigma$ & $\sigma_{T}$ \\
\hline PGA & -0.0208 & -0.0138 & & 0.0007 & -0.0368 & -0.0473 & -0.8958 & -0.7083 & -0.5789 & -0.3986 & 0.3833 & 0.0541 & 0.3871 \\
\hline 0.01 & 0.0208 & 0.0139 & 5.0 & 0.0007 & -0.0368 & -0.0473 & -0.8956 & -0.7080 & -0.5785 & -0.3984 & & 0.0541 & 0.3871 \\
\hline 0.02 & 0.0208 & 0.0138 & .0 & .0007 & -0.0368 & -0.0473 & 0.8957 & -0.7082 & -0.5787 & -0.3985 & 0.3833 & 0.0541 & .3871 \\
\hline 0.03 & -0.0300 & 0.0145 & 5.0 & 0.0007 & -0.0282 & -0.0405 & -0.8248 & -0.6258 & -0.5163 & & & 0.0668 & 0.3891 \\
\hline & -0.0533 & 0.0215 & 5.0 & 0.0012 & -0.0085 & -0.0274 & -0.6357 & -0.3627 & -0.3571 & -0.2129 & & & 0.3993 \\
\hline & .0518 & 0.0534 & & 0016 & 0.0070 & -0.0105 & 0.4159 & -0.1603 & -0.1703 & -0.0 & 0.4013 & 0.0911 & 0.4115 \\
\hline 0.06 & -0.0409 & -0.0430 & 5.0 & 0.0015 & 0.0302 & 0.0096 & -0.6241 & & -0.1779 & -0.1091 & & & 0.4069 \\
\hline 0.07 & 0.0015 & -0.0196 & 5.0 & & 0.0167 & -0.0202 & -0.9448 & -0.7360 & -0.3703 & -0.3672 & & & 0.4205 \\
\hline 0.08 & 0.0226 & -0.0213 & 0 & .0014 & 0.0081 & -0.0295 & -1.0769 & -0.9312 & -0.4386 & -0.4815 & 4519 & 398 & 0.4537 \\
\hline 0.09 & 0.0548 & 0.0589 & 5.0 & 0.0015 & 0.0139 & -0.0138 & -1.0381 & -1.0019 & -0.5095 & -0 & 0.4830 & 496 & 0.4855 \\
\hline 0.1 & & 0.0391 & 5.0 & & 0.0095 & -0.0377 & -1.0350 & -1.0519 & -0.5580 & -0.5961 & & & 0.4885 \\
\hline 0.12 & 0.0598 & -0.0705 & 5.0 & 0.0020 & -0.0325 & -0.0752 & -1.0169 & -0.8637 & -0.4637 & -0.4797 & 0.4636 & 0.0000 & 0.4636 \\
\hline 0.14 & .0662 & -0.0594 & 5.0 & 0.0013 & -0.0851 & -0.1183 & -1.0767 & -0.8918 & -0.4751 & -0.5 & 0.4555 & 0.0000 & 0.4555 \\
\hline 0.15 & & 0.0164 & 5.0 & 0.0005 & -0.1099 & -0.1247 & -1.2513 & -1.0190 & -0.5480 & & & & 0.4456 \\
\hline 0.16 & .0554 & 0.0150 & 5.0 & -0.0004 & -0.1293 & -0.1282 & -1.3563 & -1.1410 & -0.6863 & -0.7648 & 0.4500 & 0.0000 & 0.4500 \\
\hline 0.18 & 0471 & 0.0431 & 5.0 & -0.0011 & -0.1344 & -0.1290 & -1.3775 & -1.2687 & -1.0625 & -0.8336 & 0.5184 & 0.0000 & 0.5184 \\
\hline 0.2 & & 0.0628 & 5.0 & -0.0008 & -0.1326 & -0.1205 & -1.4771 & -1.3210 & -1.3199 & -0.8752 & & & 0.5602 \\
\hline 0.25 & 0067 & 0.1037 & 5.0 & -0.0007 & -0.1385 & -0.1382 & -1.6694 & -1.3403 & -1.8761 & -0.9300 & 0.5744 & 001 & 0.5744 \\
\hline 0.3 & 0106 & 0.0971 & 5.0 & -0.0005 & -0.0894 & -0.1223 & -1.7577 & -1.3982 & -1.7922 & -0.8165 & 0.4577 & 0.0000 & 0.4577 \\
\hline 0.35 & .0100 & & 5.0 & & -0.0464 & -0.0579 & -1.8150 & -1.3918 & & -0.7641 & & & 0.4174 \\
\hline 0.4 & & & 5.0 & -0.0009 & -0.0292 & -0.0398 & -1.7892 & -1.4175 & -1.8486 & -0.9 & & & 0.4268 \\
\hline 0.45 & 0137 & 0.0953 & 5.0 & -0.0005 & -0.0064 & -0.0507 & -1.6918 & -1.3483 & -1.7701 & -1. & 0.4 & 001 & 0.4029 \\
\hline 0.5 & & 0.1073 & 5.0 & -0.0019 & 0.0071 & 0.0114 & -1.7623 & -1.4036 & -1.8385 & -1.3617 & & 0.0000 & 0.4023 \\
\hline 0.6 & 0097 & & 5.0 & -0.0023 & & 0.0291 & -1.7369 & -1.4483 & -1.8941 & -1.6052 & & & 0.4162 \\
\hline 0.7 & -0.0028 & 1481 & 5.0 & -0.0025 & 0.0274 & 0.0397 & -1.6625 & -1.4217 & -1.8745 & -1 & & 000 & 0.3903 \\
\hline 0.8 & 0.0024 & 0.1515 & 5.0 & -0.0026 & 0.0465 & 0.0365 & -1.5818 & -1.4418 & -1.8790 & -2.0059 & 0.3867 & 0.0000 & 0.3867 \\
\hline 0.9 & 0.0031 & 401 & 5.0 & -0.0027 & 901 & 0.0563 & -1.5403 & -1.4147 & -1.8 & -2.0 & & & 0.3756 \\
\hline 1 & .0204 & .1325 & 5.0 & -0.0029 & 0.0848 & 0.0463 & -1.5981 & -1.4508 & -1.8171 & -2.0936 & 0.3735 & 428 & 0.3759 \\
\hline 1.25 & & & 5.0 & -0.0036 & & 0.0575 & -1.7068 & -1.6421 & -1.9613 & -2.1463 & & & 0.3671 \\
\hline 1.5 & 0.0312 & 0.1447 & 5.0 & -0.0040 & 0.1233 & 0.0485 & -1.5790 & -1.5867 & -1.8010 & -1.9432 & 0.3645 & 0.0696 & 0.3711 \\
\hline 2 & 0.0007 & .1688 & 5.0 & -0.0034 & & & -1.4742 & 096 & 1.7076 & 874 & 624 & 871 & 0.3727 \\
\hline 2.5 & & & 5.0 & -0.0034 & & -0.0489 & -1.5749 & -1.6315 & -1.7002 & -1.7152 & & & 0.3617 \\
\hline 3 & 0.0176 & & 5.0 & -0.0044 & 0.0239 & -0.0527 & -1.5812 & -1.7290 & -1.7698 & -1.7731 & 0.3543 & 0.0787 & 0.3630 \\
\hline 3.5 & 0.0007 & .1910 & 5.0 & -0.0042 & 0.0320 & -0.0347 & -1.5681 & -1.6556 & -1.7060 & -1.6887 & 0.3535 & 819 & 0.3629 \\
\hline 4 & 0.0003 & & 5.0 & -0.0036 & 0.0120 & -0.0717 & -1.6876 & -1.6871 & -1.7554 & -1.7169 & 0.3576 & 0.0888 & 0.3685 \\
\hline 4.5 & -0.0008 & 0.2103 & 5.0 & -0.0040 & 0.0226 & -0.0430 & -1.7306 & -1.7230 & -1.7923 & -1.7236 & 0.3637 & 0.0793 & 0.3722 \\
\hline 5 & 0.0075 & 0.2150 & 5.0 & -0.0042 & 0.0114 & -0.0594 & -1.7913 & -1.7552 & -1.8328 & -1.7459 & 0.3620 & 0.0741 & 0.3695 \\
\hline 6 & 0.0239 & 0.2222 & 5.0 & -0.0050 & 0.0148 & -0.0104 & -1.9068 & -1.8692 & -1.9437 & -1.8218 & 0.3665 & 0.0649 & 0.3722 \\
\hline 7 & 0.0198 & 0.2275 & 5.0 & -0.0050 & 0.0334 & -0.0012 & -1.9274 & -1.8821 & -1.9525 & -1.8177 & 0.3702 & 0.0663 & 0.3761 \\
\hline 8 & 0.0023 & 0.2085 & 5.0 & -0.0045 & 0.0485 & 0.0044 & -1.7867 & -1.7459 & -1.8251 & -1.6754 & 0.3760 & 0.0703 & 0.3825 \\
\hline 9 & -0.0270 & 0.2079 & 5.0 & -0.0042 & 0.0381 & 0.0033 & -1.6550 & -1.6129 & -1.7189 & -1.5270 & 0.3744 & 0.0739 & 0.3816 \\
\hline 10 & -0.0376 & 0.1910 & 5.0 & -0.0035 & 0.0316 & -0.0210 & -1.5632 & -1.4993 & -1.6126 & -1.4024 & 0.3731 & 0.0694 & 0.3795 \\
\hline
\end{tabular}




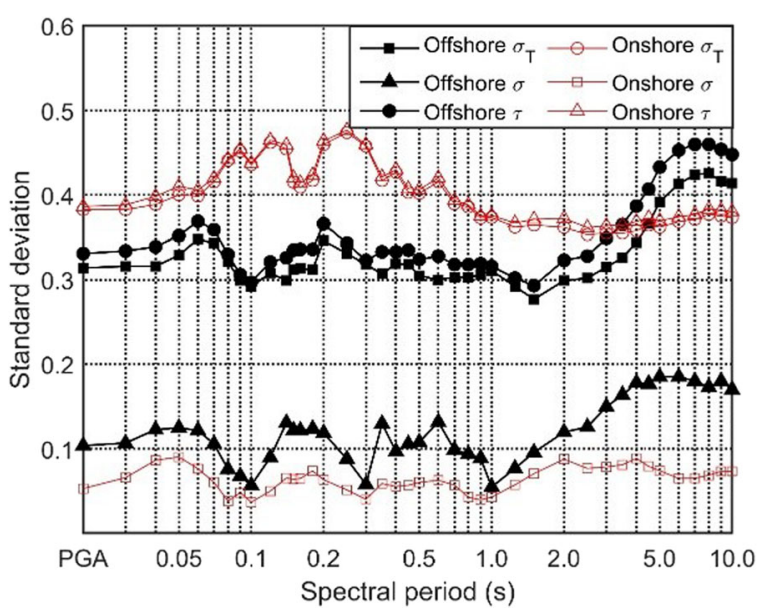

Fig. 5 Variations of standard deviations of the offshore and onshore $V / H$ model

As local site geologies between the offshore sites are not uniform (Dhakal et al. 2017), we compared differences in offshore $\mathrm{V} / \mathrm{H}$ ratios among the offshore sites as shown in Fig. 12. The individual site term $S_{1}$ was used for comparisons in Fig. 11, but differences between the offshore sites are not considered in Fig. 11. Most of the offshore sites (KNG201, KNG203, KNG205, and KNG206) have a similar spectral shape, and the offshore $\mathrm{V} / \mathrm{H}$ ratios observed in the four offshore sites are much smaller than the onshore $V / H$ ratios for periods of less than $1.0 \mathrm{~s}$ and are comparable for longer periods. However, the offshore $V / H$ ratios of KNG202 and KNG204 are apparently larger than those of the other four offshore sites and are comparable or even larger than the onshore $\mathrm{V} / \mathrm{H}$ ratios for short and moderate periods. The large variability of $V / H$ ratios in the offshore sites shows that the mean offshore $V / H$ ratio of the offshore sites results in significant levels of uncertainty, and therefore, the site-specific studies for offshore $\mathrm{V} / \mathrm{H}$ ratios are needed. The offshore $V / H$ ratios are much different between offshore sites even with similar water depth, e.g., KNG201 and KNG202 from Fig. 12a, b. Therefore, the effect of water depth is unclear from this study and needs further investigation in the future by accounting for the water depth and the sediment thickness under offshore sites.

Therefore, the prediction model used in this study considers the effect of moment magnitudes, hypocentral distances, focal depths, tectonic source types, and site differences. Among these explanatory variables, the individual site term mainly affects the spectral shape of the offshore $V / H$ ratio, and the magnitude has a significant influence on the offshore $V / H$ ratio while the effects of the hypocentral distance and tectonic source type are not as obvious
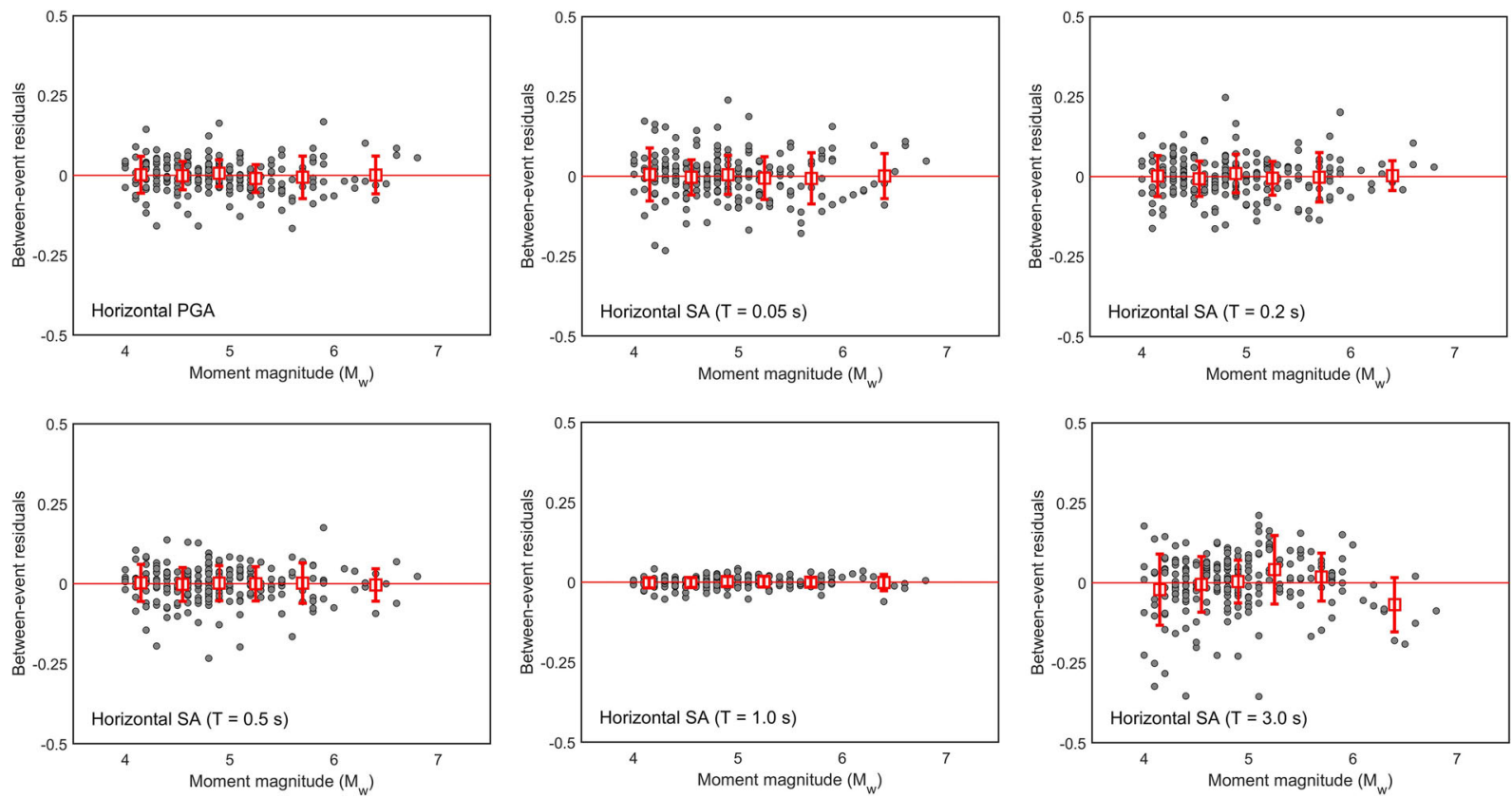

Fig. 6 Between-event residual distribution against the moment magnitude of the offshore $V / H$ model for PGA and five spectral periods $(T=$ $0.05,0.2,0.5,1.0$, and $3.0 \mathrm{~s}$ ) 

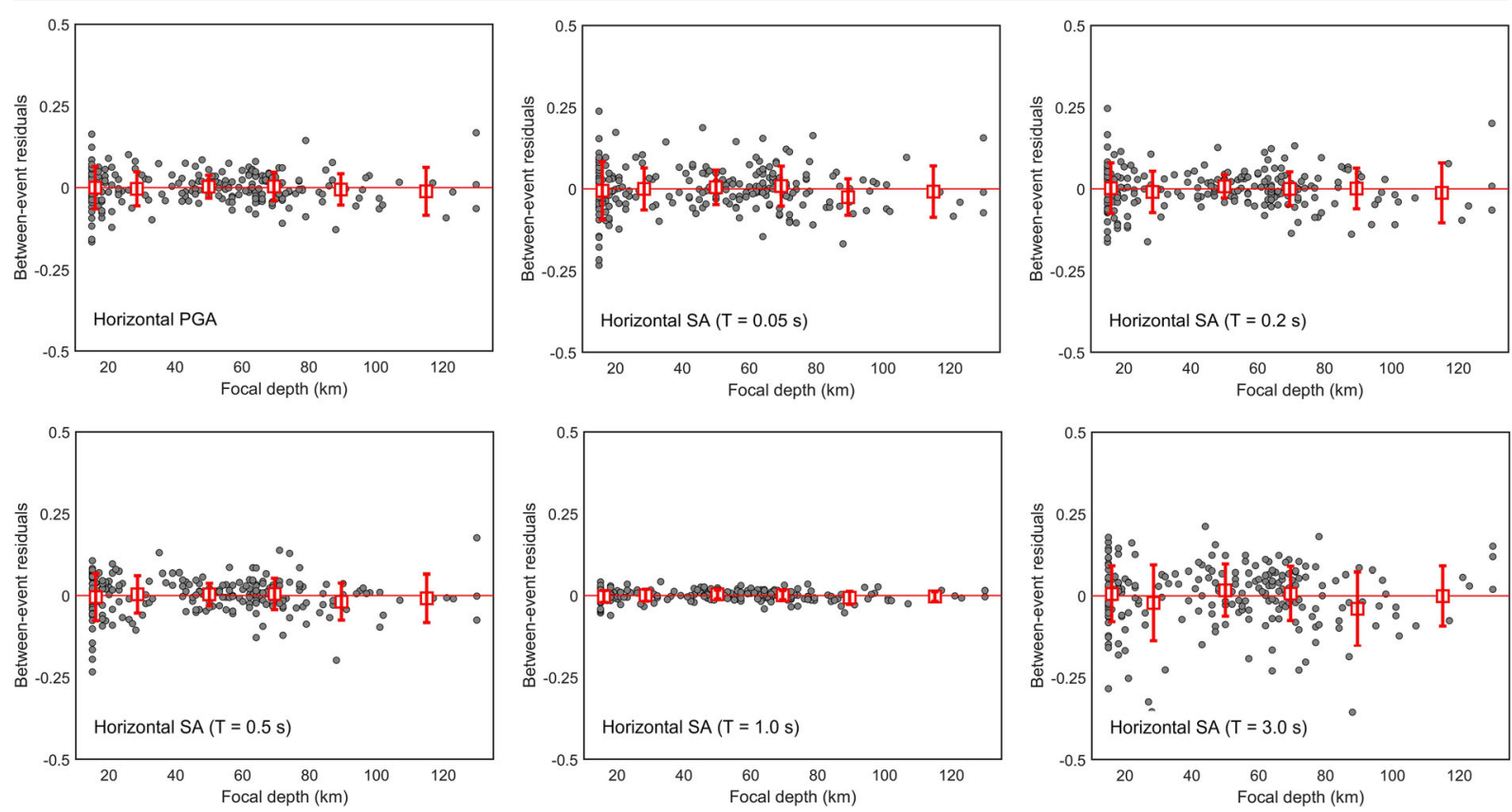

Fig. 7 Between-event residual distribution against the focal depth of the offshore $V / H$ model for PGA and five spectral periods $(T=0.05$, $0.2,0.5,1.0$, and $3.0 \mathrm{~s})$

as the effect of the magnitude. Given the large differences observed in offshore and onshore $V / H$ ratios, the combination of vertical and horizontal ground motions for seismic analysis does not need to follow the recommendation to use a $\mathrm{V} / \mathrm{H}$ ratio of 0.5 for the seismic analysis of an offshore platform.
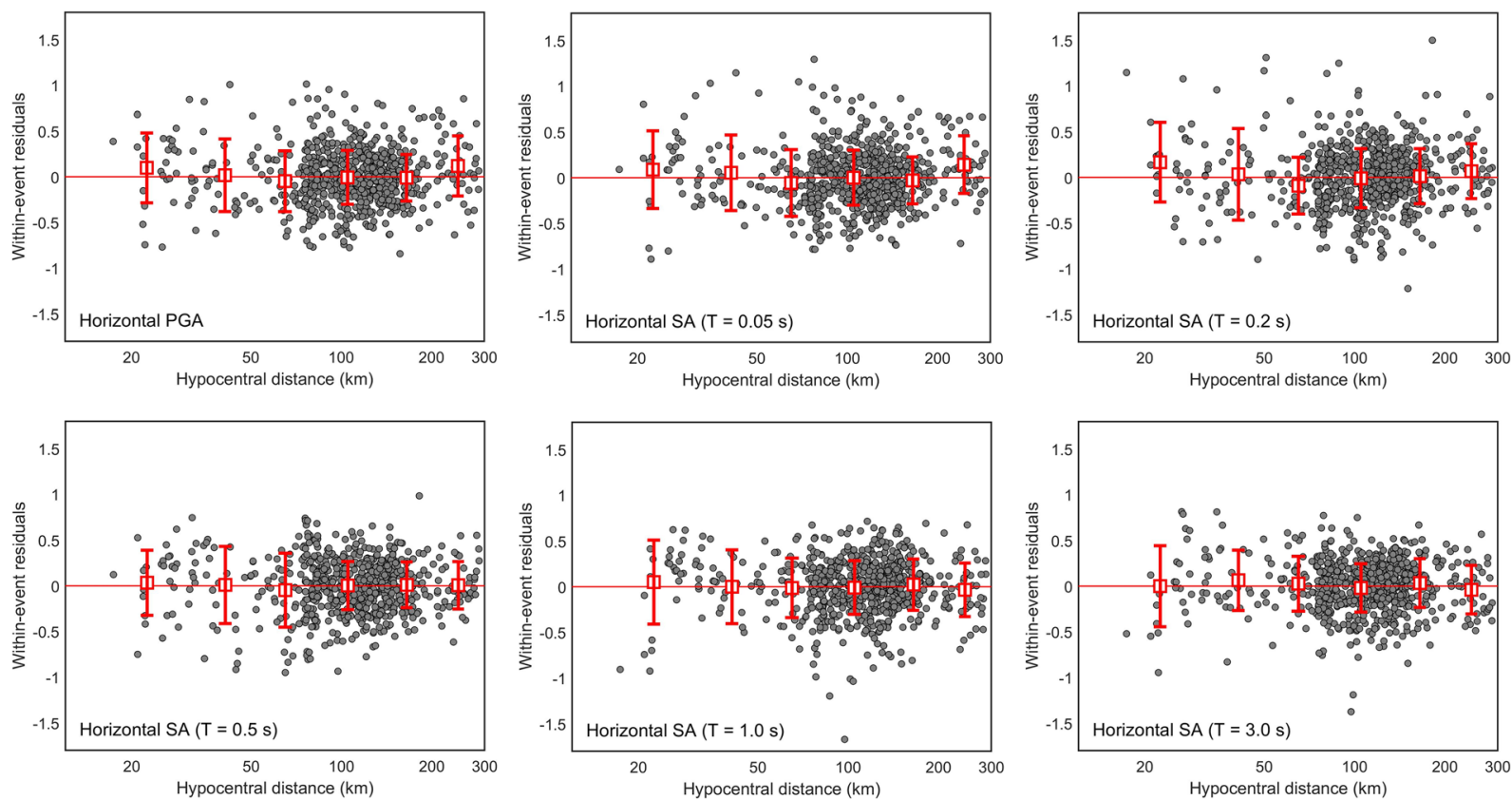

Fig. 8 Within-event residual distribution against the hypocentral distance of the offshore $V / H$ model for PGA and five spectral periods $(T=$ $0.05,0.2,0.5,1.0$, and $3.0 \mathrm{~s})$ 

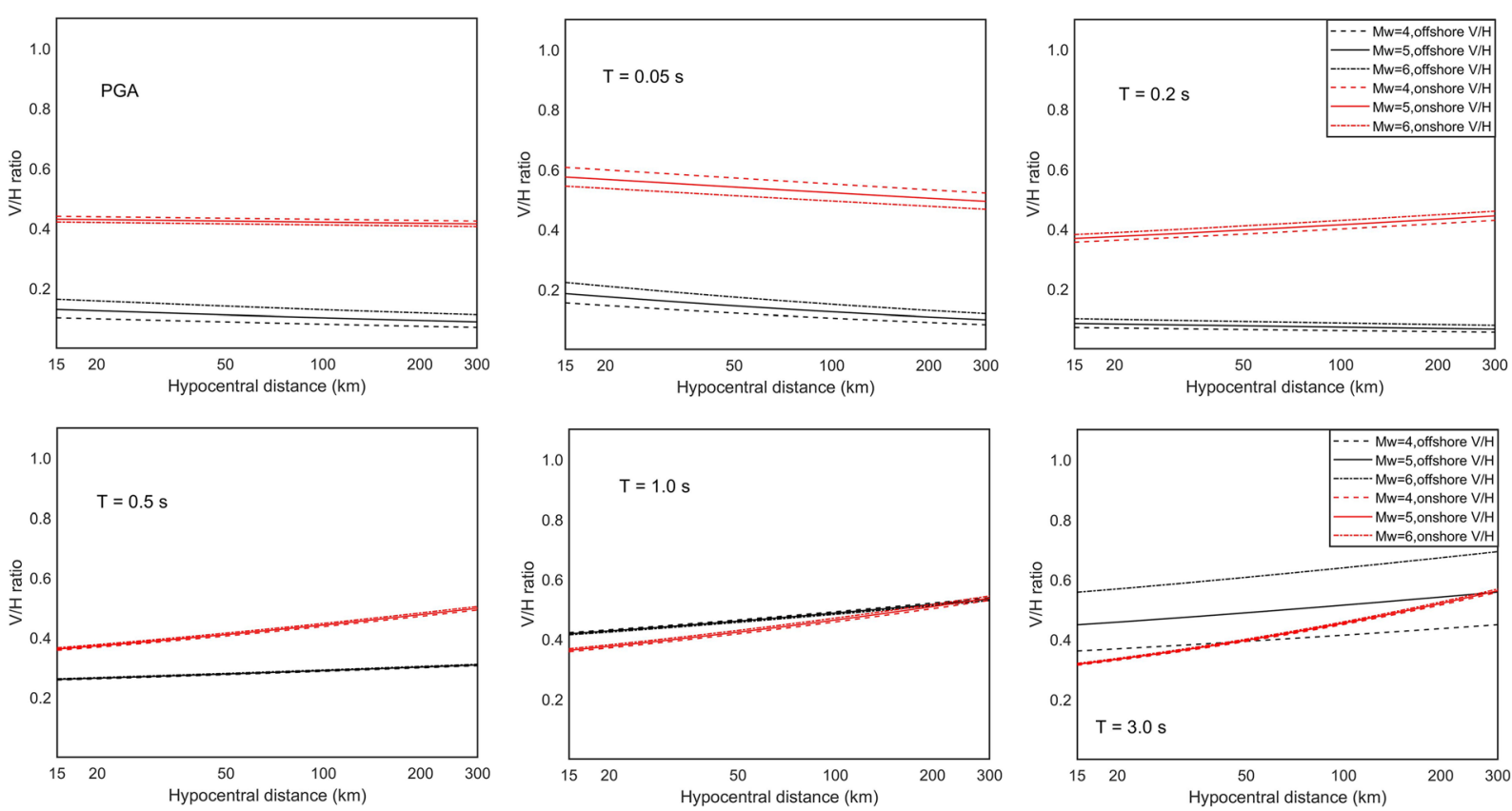

Fig. 9 Varying trend of the offshore and onshore $V / H$ ratio of given periods (PGA and $T=0.05,0.2,0.5,1.0$, and $3.0 \mathrm{~s}$ ) with the hypocentral distance by setting the magnitudes of 4,5 , and 6 ,

respectively, focal depth of $20 \mathrm{~km}$, the tectonic source type of the crustal earthquake, an $S_{4}$ individual site term for offshore sites, and an $\mathrm{SC}_{2}$ site class term for onshore sites

\section{Summary and conclusions}

A prediction model for vertical-to-horizontal $(V / H)$ response spectral ratios of offshore ground motions for the offshore area off Sagami Bay accounting for tectonic source types and focal depths was developed in this study. The onshore $V / H$ model derived from an onshore dataset is also presented for comparisons. The prediction errors of our offshore $\mathrm{V} / \mathrm{H}$ models are at least as low as those reported in other studies. The conventional

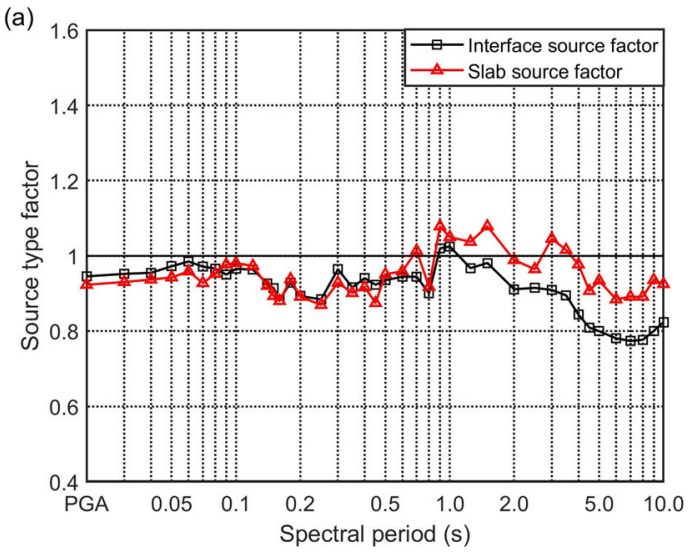

residual analysis shows that our offshore $V / H$ model is not biased with regard to magnitude, hypocentral distance, or focal depth. In the present model, predictions made in a near-source offshore region are not as reliable as predictions made on the moderate or far fields, as the offshore strong motion dataset does not include nearsource records for hypocentral distances of $1-15 \mathrm{~km}$. The magnitude range of the data for offshore models is $4.0-6.8$, and the hypocentral distance range is $15-$ $300 \mathrm{~km}$.

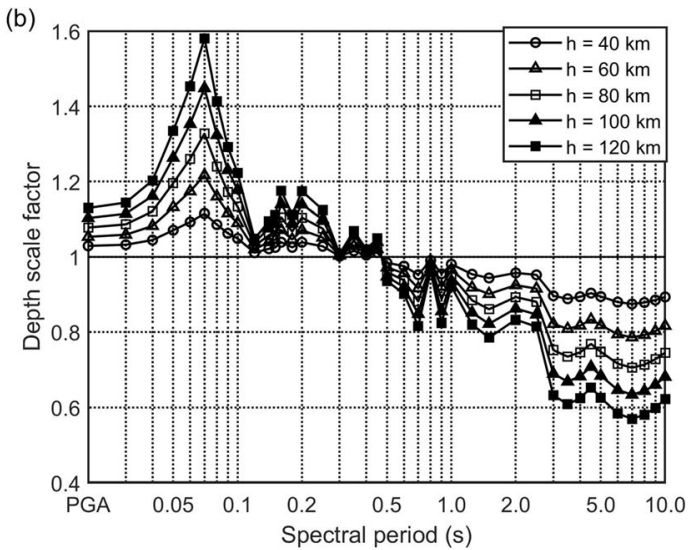

Fig. 10 Scale factors for the a source types with respect to crustal events for the offshore $V / H$ model and b focal depth with respect to events with a focal depth of $h=15 \mathrm{~km}$ or less for the offshore $V / H$ model 

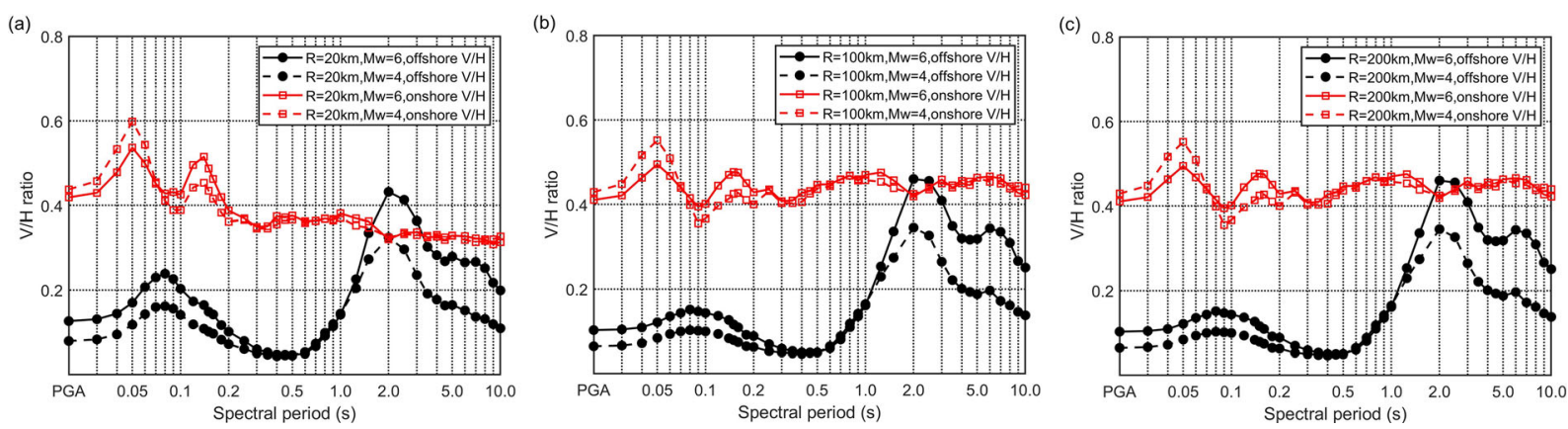

Fig. 11 Variations in the predicted median $V / H$ response spectral ratio of the offshore and onshore ground motions for specific magnitude and distance combinations for a crustal event with a focal depth of $20 \mathrm{~km}$, using $S_{1}$ individual site term for offshore sites and $\mathrm{SC}_{2}$ site class term for onshore sites
As local site geologies of offshore sites are not uniform and as corresponding site condition data are unavailable, individual site terms were used for offshore sites in the offshore $V / H$ model while site class terms were used for onshore sites in the onshore model. The regression results show that the hypocentral distance and tectonic source type have little influence on the offshore $V / H$ ratios, but the magnitude and focal depth have a significant influence on the offshore $V / H$ ratios. A direct comparison of offshore and onshore $V / H$ ratios shows that the offshore $V / H$ ratios are much smaller than the onshore $V / H$ ratios for periods of less than $1.0 \mathrm{~s}$ and are comparable or even larger for periods of longer than $1.0 \mathrm{~s}$. The deep deposition soil layer may amplify both horizontal and vertical ground motions. However, the water layer may reduce the amplitude of vertical motions, and this reduction decreases as periods increase.

Both horizontal and vertical offshore response spectra are significantly larger than onshore response spectra except that vertical response spectra for short moderate periods $(T<1.0 \mathrm{~s})$ are slightly smaller than those of onshore motions (Hu et al. 2020). Therefore, the observed reduction in the offshore $V / H$ ratios may also reflect the combined effect of water layer and the deep deposition layer. Due to the observed amplification in offshore motions across the entire period band (Hu et al., 2020), the common practice of selecting onshore records for the seismic design of offshore structures is (a)
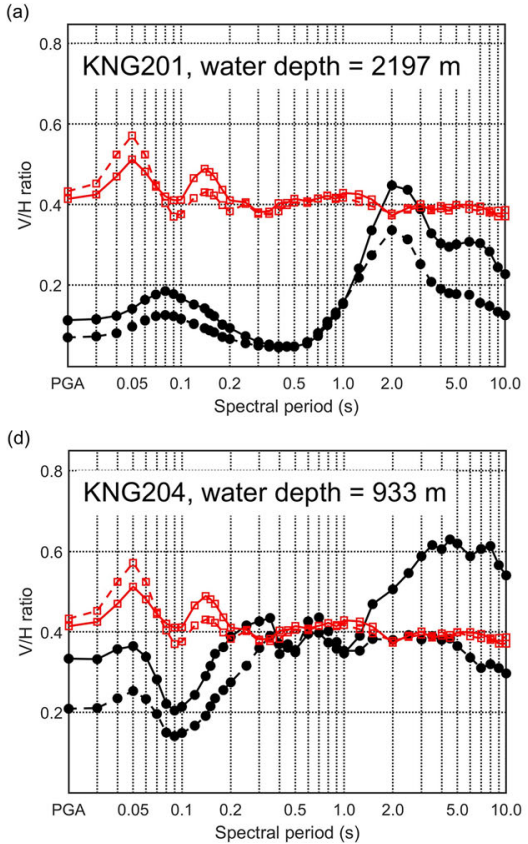

(b)
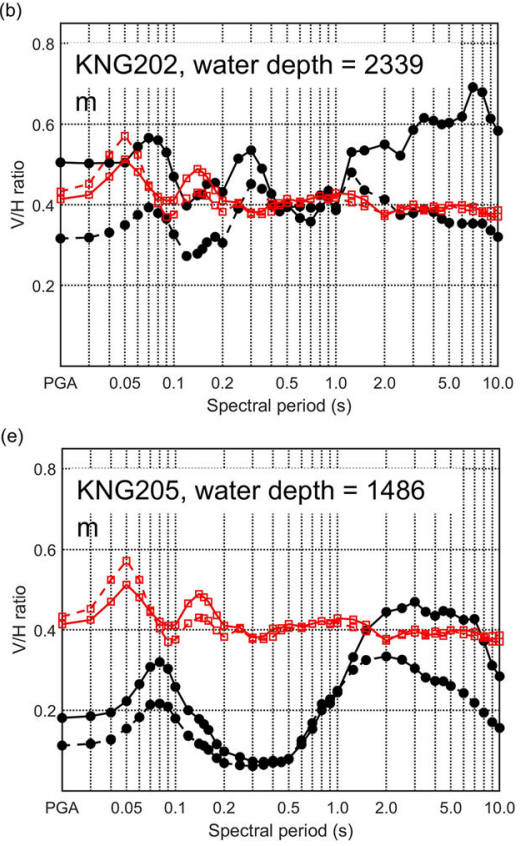

(c)

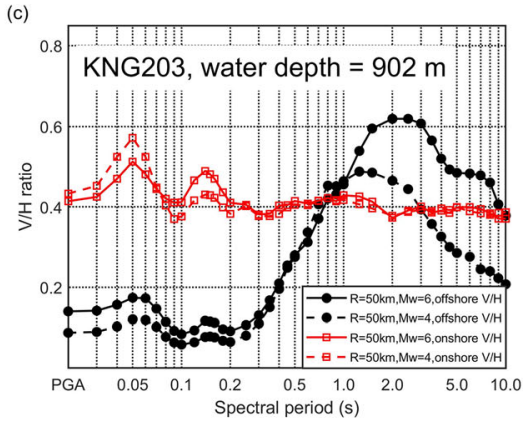

(f)

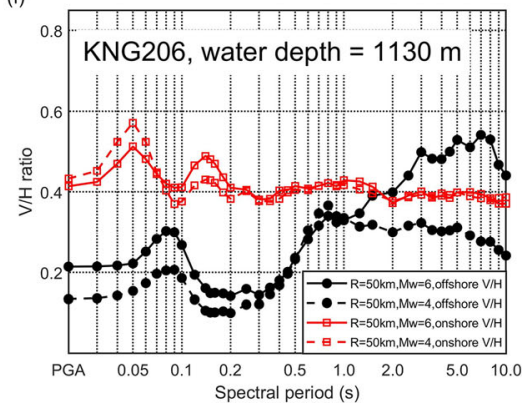

Fig. 12 Comparison between the predicted offshore and onshore $V / H$ ratio for different offshore sites and onshore class with $\mathrm{SC}_{2}$ site class 
inappropriate. Hence, the offshore $V / H$ model can facilitate the construction of the vertical response spectrum in PSHA and can be used in seismic analysis for the combined input of vertical and horizontal ground motions.

Acknowledgments We wish to thank the anonymous reviewers and the editors for their constructive comments. We would like to acknowledge the National Research Institute for Earth Science and Disaster Prevention (K-NET, F-net) for providing the strong ground motion data.

Funding information This work was supported by the National Natural Science Foundation of China (U1939210, 51578516), National Key R\&D Program of China (2017YFC1500403), and Heilongjiang Touyan Innovation Team Program.Data availabilityThe strong motion records are from K-NET (http://www.kyoshin.bosai.go.jp/, last accessed November 2019), which is operated by the National Research Institute for Earth Science and Disaster Prevention (NIED) of Japan. The moment magnitudes and focal mechanism solutions of the events are from F-net, which is also operated by the NIED. The information regarding the earthquake events is from the Japan Meteorological Agency (JMA) catalogs (http://www.hinet.bosai.go. jp/REGS/JMA/, last accessed November 2019). The electronic supplement includes the detailed information of earthquakes used in this study and figures of residual analyses of the vertical offshore and onshore attenuation models.

Open Access This article is licensed under a Creative Commons Attribution 4.0 International License, which permits use, sharing, adaptation, distribution and reproduction in any medium or format, as long as you give appropriate credit to the original author(s) and the source, provide a link to the Creative Commons licence, and indicate if changes were made. The images or other third party material in this article are included in the article's Creative Commons licence, unless indicated otherwise in a credit line to the material. If material is not included in the article's Creative Commons licence and your intended use is not permitted by statutory regulation or exceeds the permitted use, you will need to obtain permission directly from the copyright holder. To view a copy of this licence, visit http://creativecommons.org/licenses/by/4.0/.

\section{References}

Abrahamson NA, Youngs RR (1992) A stable algorithm for regression analysis using the random effect model. Bull Seismol Soc Am 82(1):505-510

Abrahamson N, Gregor N, Addo K (2016) BC hydro ground motion prediction equations for subduction earthquakes. Earthquake Spectra 32(1):23-44

Akkar S, Sandıkkaya M, Аy BÖ (2014) Compatible groundmotion prediction equations for damping scaling factors and vertical-to-horizontal spectral amplitude ratios for the broader Europe region. Bull Earthq Eng 12:517-547
Aoi S, Kunugi T, Fujiwara H (2004) Strong-motion seismograph network operated by NIED: K-NET and KiK-NET. J Jpn Assoc Earthq Eng 4(3):65-74

Bommer JJ, Akkar S, Kale Ö (2011) A model for vertical-tohorizontal response spectral ratios for Europe and the Middle East. Bull Seismol Soc Am 101:1783-1806

Boore DM, Bommer JJ (2005) Processing of strong-motion accelerograms: needs, options and consequences. Soil Dyn Earthq Eng 25:93-115

Boore DM, Smith CE (1999) Analysis of earthquake recordings obtained from the Seafloor Earthquake Measurement System (SEMS) instruments deployed off the coast of southern California. Bull Seismol Soc Am 89(1):260-274

Boore DM, Jorner WB, Fumal TE (1997) Equations for estimating horizontal response spectra and peak acceleration from western North American earthquakes: a summary of recent work. Seismol Res Lett 68:128-153

Boore DM, Stephens CD, Joyner WB (2002) Comments on baseline correction of digital strong-motion data: examples from the 1999 Hector Mine, California, earthquake. Bull Seismol Soc Am 92(4):1543-1560

Boore DM, Thompson EM, Cadet H (2011) Regional correlations of VS30 and velocities averaged over depths less than and greater than 30 meters. Bull Seismol Soc Am 101(6):30463059

Boore DM, Stewart JP, Seyhan E, Atkinson GM (2014) NGAWest2 equations for predicting PGA, PGV, and 5\% damped PSA for shallow crustal earthquakes. Earthquake Spectra 30(3):1057-1086

Bozorgnia Y, Campbell KW (2016) Ground motion model for the vertical-to-horizontal $(\mathrm{V} / \mathrm{H})$ ratios of $\mathrm{PGA}, \mathrm{PGV}$, and response spectra. Earthquake Spectra 32(2):951-978

Chen B, Wang D, Li H, Sun Z, Shi Y (2015) Characteristics of earthquake ground motion on the seafloor. J Earthq Eng 19(6):874-904

Chen B, Wang D, Li H, Sun Z, Li C (2017) Vertical-to-horizontal response spectral ratio for offshore ground motions: analysis and simplified design equation. J Cent South Univ 24(1): 203-216

Dhakal YP, Aoi S, Kunugi T, Suzuki W, Kimura T (2017) Assessment of nonlinear site response at ocean bottom seismograph sites based on S-wave horizontal-to-vertical spectral ratios: a study at the Sagami Bay area K-NET sites in Japan. Earth Planets Space 69:29

Diao H, Hu J, Xie L (2014) Effect of seawater on incident plane P and SV waves at ocean bottom and engineering characteristics of offshore ground motion records off the coast of southern California, USA. Earthq Eng Eng Vib 13(2):181-194

Eguchi T, Fujinawa Y, Fujita E, Iwasaki SI, Watabe I, Fujiwara H (1998) A real-time observation network of ocean-bottomseismometers deployed at the Sagami trough subduction zone, central Japan. Mar Geophys Res 20:73-94

Gülerce Z, Abrahamson NA (2011) Site-specific design spectra for vertical ground motion. Earthquake Spectra 27(4):10231047

Hu J, Tan J, Zhao JX (2020) New GMPEs for the Sagami Bay region in Japan for moderate magnitude events with emphasis on differences on site amplifications at the seafloor and land seismic stations of K-NET. Bull Seismol Soc Am (accepted) 
Kanazawa T (2013) Japan Trench earthquake and tsunami monitoring network of cable-linked 150 ocean bottom observatories and its impact to earth disaster science. Underwater Technology Symposium (UT), 2013 IEEE International:1-5

Kaneda Y, Kawaguchi K, Araki E et al (2015) Development and application of an advanced ocean floor network system for megathrust earthquakes and tsunamis. In: Favali P et al (eds) Seafloor observatories. Springer Praxis Books, pp 643-662

Li C, Hao H, Li H, Bi K (2015) Theoretical modeling and numerical simulation of seismic motions at seafloor. Soil Dyn Earthq Eng 77:220-225

Molas GL, Yamazaki F (1995) Attenuation of earthquake ground motion in Japan including deep focus events. Bull Seismol Soc Am 85:1343-1358

Montalva GA, Bastías N, Rodriguez-Marek A (2017) Groundmotion prediction equation for the Chilean subduction zone. Bull Seismol Soc Am 107(2):901-911

Morikawa N, Sasatani T (2004) Source models of two large intraslab earthquakes from broadband strong ground motions. Bull Seismol Soc Am 94(3):803-817

Otsuka K (1985) Processes and faces of active trough filling up sediments - geology of upper quaternary sediments in the northernmost areas of the Sagami and Suruga Troughs. Geosciences Reports, Shizuoka University, pp 57-117 (In Japanese)

RP2A-WSD A P I (2014) Recommended practice for planning, designing and constructing fixed offshore platforms-working stress design. American Petroleum Institute, Houston

Soghrat MR, Ziyaeifar M (2016) A predictive equation for vertical-to-horizontal response spectral ratios in Northern Iran. Bull Seismol Soc Am 106(1):123-140
Stewart JP, Boore DM, Seyhan E, Atkinson GM (2016) NGAWest2 equations for predicting vertical component PGA, PGV, and 5\%-damped PSA from shallow crustal earthquakes. Earthquake Spectra 32(2):1005-1021

Strasser FO, Abrahamson NA, Bommer JJ (2009) Sigma: issues, insights and challenges. Seismol Res Lett 80(1):40-54

Takahashi T, Saiki T, Okada H et al (2004) Attenuation models for response spectra derived from Japanese strong-motion records accounting for tectonic source types. Paper 1271, presented at 13th World Conference of Earthquake Engineering, Vancouver BC, Canada

Youngs RR, Chiou S-J, Silva WJ, Humphrey JR (1997) Strong ground motion attenuation relationships for subduction zone earthquakes. Seismol Res Lett 68(1):58-73

Zhao JX, Zhang J, Asano A et al (2006) Attenuation relations of strong ground motion in Japan using site classification based on predominant period. Bull Seismol Soc Am 96(3):898-913

Zolfaghari MR, Darzi A (2019a) A prediction model for verticalto-horizontal ratios of PGA, PGV, and 5\%-damped response spectra $(0.01-10 \mathrm{~s})$ for Iran. J Seismol 23:819-837

Zolfaghari MR, Darzi A (2019b) Ground-motion models for predicting vertical components of PGA, PGV and 5\%damped spectral acceleration $(0.01-10 \mathrm{~s})$ in Iran. Bull Earthq Eng 17:3615-3635

Publisher's note Springer Nature remains neutral with regard to jurisdictional claims in published maps and institutional affiliations. 